Başvuru : 07.11.2016

Kabul : 09.01.2017

\title{
Bankalarda Örgüt Kültürünün Belirlenmesinde Alternatif Bir Yöntem Olarak Metafor Analizi ${ }^{1}$
}

\author{
Tülay Çelik ${ }^{2}$ \\ Güler Sağlam Arı ${ }^{3}$
}

Bankalarda Örgüt Kültürünün Belirlenmesinde Alternatif Bir Yöntem Olarak Metafor Analizi

Öz

Bu araştırmanın amacı, örgüt kültürünün mevcut analizlere alternatif bir yöntem olarak metaforlarla analizini gerçekleştirmektir. Bu amaçla, Tokat ili ve ilçelerinde faaliyet gösteren bir kamu bankasının şubelerinde çalışan toplam 67 kişi ile yüz yüze görüşmeler yapılmıştır. Hazırlanan standart açık uçlu görüşme formları kullanılarak katılımcılara örgüt kültürünün özelliklerini benzetmede hangi metaforları neden kullandıkları sorulmuştur. Metaforların analizi sonucunda, çalışanların örgüt kimliğini benimsedikleri, bankayı aile gibi gördükleri, takım ruhu ve müşteri odaklı bir yaklaşımla ortak bir hedef doğrultusunda hareket ettikleri belirlenmiştir. Kültürün olumsuz özellikleri; ödüllerin ve ödül standartlarının yetersiz olması, hataya tolerans gösterilmemesi, yöneticilerin hükmedici ve cezalandırıcı olması, çalışanların kendilerini güçlendirilmiş hissetmemeleri ve katı kuralların hâkim olmasıdır. Araştırma sonunda bankada güçlü bir kültürün var olduğu ve metafor analizinin örgüt kültürü analizinde betimleyici bir yöntem olarak kullanılabileceği ortaya konulmuştur.

Anahtar Kelimeler: Örgüt kültürü, bankalar, metafor, metafor analizi, nitel araştırma.
Metaphor Analysis as an Alternative Method for Determining Organizational Culture in Banks

\section{Abstract}

The aim of this study is to perform an analysis of the metaphor as an alternative to the existing analysis of organizational culture. For this aim, a total of $67 \mathrm{em}$ ployees working in Tokat city Turkey and province branches of the bank aforementioned have been interviewed. Participants having been given a set of openended questions in the interview have been asked which metaphors they use for the properties of organizational culture and why they use those metaphors. With the help of metaphor analysis, it has been established that employees, embracing customer-oriented approach, adopt the organizational identity, see the bank as a family and act within the frame of a common goal. As for the negative features to the organizational culture in the bank, it has been found that both rewards and reward standards are insufficient, no mistake can be tolerated, the managers are seen like a ruler and punisher, the employees feel not empowered and there exists strict rules within the bank. At the end of the study that there is a strong culture in the bank and has been demonstrated in the descriptive analysis of organizational culture it can be used as a method of metaphor analysis.

Keywords: Organizational culture, banks, metaphor, metaphor analysis, qualitative research.

\section{Giriş}

Toplumun üyeleri, içinde yer aldıkları toplumsal kültür ve bu kültürün inançları, değerleri ve normları çerçevesinde yaşamlarını sürdürmektedir. Örgütlerdeki bireyler, görev aldıkları örgütün kültürü ile iç içe yaşamaktadır. Örgüt kültürü liderler, üyeler, uygulamalar ile gelişen ve gelecekteki üyelere aktarılan bir sistemdir. Örgüt kültürünün öğrenilmesi, örgüt üyelerinin ve yöneticilerinin örgütün amaçlarını, stratejilerini ve politikalarını başarmasına yardımcı olmaktadır. Güçlü bir örgüt kültürünün varlığı, üyelerin ve yöneticilerin örgüt çıkarları için birlikte hareket etmesi ile sonuçlanmaktadır. Alan yazında, örgüt kültürünün anlaşıımasında, nitel

\footnotetext{
${ }^{1}$ Bu çalışma Gazi Üniversitesi Sosyal Bilimler Enstitüsü, Bankacılık Eğitimi Bilim Dalı’nda Doç. Dr. Güler Sağlam Arı danışmanlığında Tülay Çelik'in yazmış olduğu yüksek lisans tezinin genişletilmesi ile hazırlanmış, özeti ise Romanya Bükreş'te 11-13. Haziran 2015 yılında VII. European Conference on Social and Behavioral Sciences'da sözlü bildiri olarak sunulmuştur.

2 Öğr. Gör., Gaziosmanpaşa Üniversitesi Erbaa MYO, Finans-Bankacılık ve Sigorta Bölümü. tulay.celik@gop.edu.tr

${ }^{3}$ Doç. Dr., Gazi Üniversitesi IïBF, Uluslararası Ticaret Bölümü. gsaglam@gazi.edu.tr
} 
ve nicel yöntemlerden hangisinin daha etkili bir ölçüm ortaya koyacağına dair yöntemsel tartışmalar yer almaktadır (Erkmen, 2000; Danışman ve Özgen, 2003). Örgüt kültürü unsurlarının incelenmesi ve kültürün temeli sayılan varsayımların açığa çıkarılması örgütün sembolik boyutlarının doğru anlaşılmasına bağlıdır. Semboller örgütün karmaşık yapısına ve örgütsel yaşama ilişkin önemli bilgiler içerir (Sargut, 2001: 75). Dil, örgüt kültürünün bütünleştirici, karmaşık ve sembolik bir unsurudur. Kavramlar, inançlar, normlar, değerler ve kültürün pratiklerini temsil ederken, insanların düşünme biçimlerini de etkiler. Örgüt kültüründeki sembolik unsurları anlamanın yollarından birisi de bireylerin kullandığı metaforlardır. Metaforlar, bireylerin durumlara dair yargılarını, kendilerini zor durumda bırakabilecek doğrudan ifadeler yerine benzetmelerle açıklamaya çalışmaktadır. Metafor analizi bireylerin kendilerini sarmalayan kültürel özellikler ve bu kültürdeki deneyim ve sosyalleşmelerinin derecesine dayalı olarak kültüre dair ipuçları vermektedir. Metafor analizi için gerçekleştirilen görüşmeler, görüşme yapılan kişinin örgütü ve örgütün kendisini nasıl gördüğü, üyelerin kendilerini ve diğerlerini nasıl gördüğü, örgütün amaçlarını nasıl gerçekleştirdiğine ilişkin olarak elde edilen verileri içerir (Billups, 2011a, 2011b).

Fon arz edenler ile fon talep edenler arasında aracılık hizmeti yapan bankalar, Türkiye'de finansal sektörün önemli bir bölümünü oluşturmaktadır. Cumhuriyetin kurulması ile birlikte kamu ve özel kesim sermayeli ikili yapıda gelişmiş olan sektör, 2001 krizi sonrası sorunlu bankaların sistemden çıkması, yeni yasal düzenlemelerin oluşturulması, küçük ve orta ölçekli bankaların birleştiği, yabancı bankaların da sisteme artarak girdiği, rekabetin yoğunlaştığı ve özellikle büyük bankaların daha rekabetçi davrandığı bir yapı arz etmektedir (Coşkun ve diğ,2012). Bankacılık sektöründeki değişim ve gelişmeler ekonominin yapısını doğrudan etkilemektedir. Bankaların mali yapıları kadar, güçlü bir örgüt kültürüne sahip olmaları da başarılarında ve rekabet güçlerinde önemli bir unsurdur. Bu çalışmada bankacılık sektöründen bir örnek üzerinde, örgüt kültürünün, çalışanlar tarafından nasıl algılandığı, metaforlar yardımı ile ortaya konulmaktadır. Çalışmanın bundan sonraki kısmında öncelikle örgüt kültürü ve metafor analizine ilişkin literatür aktarılmıştır. Sonrasında Tokat ili ve ilçelerinde bir kamu bankasının şubelerinde gerçekleştirilen görüşme sonuçları metafor analizi ile değerlendirilmiştir. Araştırmada elde edilen sonuçlar, banka çalışanları ve yöneticilere örgüt kültürünün güçlü ve zayıf yönlerini görebilme, daha güçlü bir örgüt kültürünün oluşması ve bankalar arasında yaşanan rekabette rekabet üstünlüğü sağlama açısından önemli ipuçları sunmaktadır.

\section{Kavramsal Çerçeve}

Örgüt kültürü araştırmaları, 1940'larda Lewin'in "eylemli araştırma" yaklaşımı ve bu yaklaşımdan etkilenen araştırmacıların yaptıkları çalışmalarla başlamıştır. 1950 ve 1960 'larda Katz ve Kahn gibi araştırmacıların grup çalışmalarındaki gelişmelerin etkisiyle yaptıkları, örgütsel norm ve tutumların tanımlandığı sistem kavramını kullanan çalışmalarla devam etmiştir. 1970'lerde Silwerzweig ve Allen'in makaleleri ile örgütsel davranışın anlaşılmasında önemli bir boyut olarak ele alınmaya başlamıştır (Schein, 2002). Örgüt kültürü ilk kez 1979 yılında, Pettigrew'in yazdığı (1979), antropoloji alanında kullanılan kültür kavramının yönetim ve organizasyon alanı ile ilişkilendirdiği ve kültürel unsurların örgütsel analizde nasıl kullanılabileceğini tartıştığı çalışması ile alan yazında yer almıştır. 1980'li yıllardan itibaren yoğun bir ilgi ile araştırmalara konu olmaya başlayan kavram, 1990'lara kadar açıklanmaya ve anlaşılmaya çalışılarak tartışılmıştır. 1990'lar sonrası ise örgüt kültürü, örgütsel değişkenlerle ilişkilendirilmiş, yöntemsel tartışmalar da araştırmaların odağına yerleşmiştir (Danışman ve Özgen, 2003). 
Örgüt kültürünün, tıpkı toplumsal kültür gibi, örgütlerde yer alan yerleşik kültür olduğu söylenebilir. Bir örgüt için kültür, birey için kişilik gibi saklı ancak birleştirici, anlam sağlayan, yön ve hareket veren bir temadır (Yağmurlu, 1997). Kilmann ve arkadaşları örgüt kültürünü (1985'den aktaran Fiş ve Wasti, 2009), bir topluluğu bir arada tutan ve nesiller boyu paylaşılagelen felsefeler, ideolojiler, değerler, varsayımlar, inanışlar, beklentiler, tutumlar ve normlar bütünü olarak tanımlamaktadır. Örgüt kültürü; bireylerin davranışlarını ve eylemlerini etkileyen, örgütteki temel düşünme yöntemleri, değerleri ve normlar dizisidir (Thom, 1990: 182). Alan yazında örgüt kültürü için pek çok farklı tanım yer alsa da, örgütlerde bireyleri bir arada tuttuğu, adeta bir yapıştırıcı işlevi gördüğü konusunda bir görüş birliği mevcuttur (Fiş ve Wasti, 2009).

Yeni bir üye örgüte katıldığında örgütteki yapıları hisseder ve gözlemler. Örgütün fiziksel düzeni, giyinme kuralları, insanların birbiri ile konuşma tarzı, yerin kokusu ve verdiği his, o yerin duygusal yoğunluğu ve diğer olgu ve olaylardan şirket kayıtları, ürünler, örgütün felsefesine dair bildirgeler, yıllık raporlar gibi kanıtlara kadar her şey buna dâhildir. Örgüt kültürü, kuruluşun ortak hedeflerinin başarılması, örgüt üyelerince birlik beraberlik duygusunun gelişimi, örgüt içi ve örgüt dışı gelişmelerden etkilenerek değişen çevreye uyum sağlaması nedeniyle önemlidir (Schein,2002). Her örgütün kültürü olmasına rağmen her kültür çalışanlar üzerinde aynı ölçüde etkiye sahip değildir. Örgütte temel değerlerin korunduğu ve geniş ölçüde paylaşıldığı kültürler güçlü kültürler olarak nitelendirilmektedir. Çalışanların bu temel değerleri kabul ettiği, benimsediği ve bağlı kaldığı kültürler güçlü kültürlerdir. Böyle bir kültürde çalışan davranışları, yükselmek için neler yapılması gerektiği gibi konularda bir mutabakat vardır. Güçlü kültürlerde biçimsel kural ve düzenlemeler içselleştirildiği için kontrole daha az ihtiyaç duyulur. Zayıf kültürlerde ise neyin önemli olduğu neyin önemsiz olduğu belirsizdir. Örgüt çalışanları temel değerleri öğrendikçe neyin kabul edilebilir neyin kabul edilemez olduğunu da öğrenmektedir. Güçlü kültürlerde çalışan bağlılığı ise zayıf kültürlere göre yüksektir (Robbins and Coulter,1996:82-83; Bloisi, Cook ve Hunsaker, 2003:662; DeCenzo ve Coulter,2013:41).

Örgüt kültüründeki değerler içerik ve kaynağına göre farklı şekilde sınıflanabilmektedir. Değerlerin içeriği açısından fonksiyonel ve elitist değerler, kaynağı açısından ise karizmatik ve geleneksel değerler olarak ayrılmaktadır. Fonksiyonel değerler, çalışanlara dikkate alınması gereken normatif davranış biçimleri sunar. Örneğin kalite, yenilikçilik, hız, müşteri hizmetleri gibi. Elitist değerlerde ise vurgulanan, diğer örgütlerle karşılaştırıldığında örgütün algılanan üstünlükleridir. Fonksiyonel değerler daha inşa edici bir özellik göstermekte, çalışanlara davranışlarında rehberlik etmekte yararlı iken, elitist değerler örgütle gurur duyma gibi güçlü duygular yaratmaktadır. Karizmatik değerler güçlü bir lider ve kurucu ile bu liderin kimliğiyle içselleştirilmiş bir üyeliği ifade eder. Geleneksel değerler ise, tarihsel bir geçmişle birlikte güçlü bir şekilde yerleşmiş ve sürekli hale gelmiş uygulamalarla şekillenmekte ve kuşaktan kuşağa aktarılmaktadır. Bu çerçevede, bu değerler bir arada düşünülerek fonksiyonel-geleneksel, elitist-karizmatik, fonksiyonel karizmatik ve elitist-geleneksel olarak ifade edilen değer türleri belirlenmektedir (Weiner,1988; Bloisi ve diğ.,2003:668-670).

Örgüt kültürünün ölçümü ve analizi kültür gibi gerek birey gerekse gruplar için etkili ve belirleyici bir olgunun anlaşılması açısından büyük önem taşımaktadır. Örgüt kültürünün incelenmesindeki farklı yaklaşımlar, tespitinde farklı yöntemlerin kullanılmasına neden olmuştur. Örgüt kültürü, örgütte çalışanların temel varsayımları öğrenilerek belirlenebilir. Örgüt kültürünü anlamanın yollarından birisi de bireylerin örgüt kültürünü bilfiil nasıl algıladığını bulmaktır (Hammal ve Vadi,2010). Örgüt kültürü değerler, normlar, varsayımlar gibi ögelerden olu- 
şurken semboller, hikâyeler, törenler gibi olgularla da ifade edilmektedir. Bir kısım araştırmacılar değerler, normlar, varsayımlar üzerinde dururken, diğerleri de yönetici ve astların davranış biçimleri, terfi ve teşvik gibi kültürle doğrudan ilişkili uygulamalar üzerinde durmaktadırlar. Örgüt kültürü araştırmalarında yöntem üzerine yapılan tartışmalarda nicel yöntemler, nitel yöntemler ya da karma desenlerin kullanılabileceği, yöntem tercihinin ise araştırma amacı ve paradigmalara bağlı olarak yapılabileceği önerilmektedir. Örgüt kültürünün ölçülmesinde kültür tasniflerine bağlı olarak örgüt kültürü ölçekleri, görüşme ve gözlem yöntemleri kullanılabileceği gibi çoklu ölçümlerden de yararlanılabilmektedir (Erkmen, 2000; Gizir, 2003).

Schein'e göre (2002) örgüt kültürü nicel olarak ölçülemez, kalitatif araştırmalar kullanılmaııdır. Çünkü kültürün temeli sayılan varsayımlar kişilerin farkında olmadıkları, bilinç dışı öğelerdir ve tanımlanmaları zordur. Ayrıca, her örgütün kendine has bir kültüre sahip olması, standart ölçme yöntemleri için engel teşkil etmektedir. Bunun için de örgüt üyeleriyle derinlemesine mülakatlar yapılmasını önermektedir. Bu zor bir iştir. Çünkü kültürün temeli sayılan varsayımlar çok derinlerde gömülüdürler ve ancak örgüt dışından kişilerce yapılacak etkileşimsel araştırmalardan sonra yüzeye çıkarılabilirler. Ayrıca varsayımlar, iş ilişkilerini de etkileyen duyguları kapsadıkları için, ölçme çalışmaları; değerler, kurallar ve somut kültür öğelerini dikkate almalıdır (Schein,2002). Geertz de kültürün (1973'den aktaran Yağmurlu,1997), insanın kendi ördüğü belirlilik ağları olduğunu, insanın bu ağlar üzerinde durduğunu, analizinin de kuralların araştırıldığı ampirik bir bilim değil, anlamın araştırıldığı yorumlayıcı bir alan olması gerektiğini söylemektedir. Analiz ise, kültürün kendisini gösterdiği üç şeyi; gözlemlenebilir nesneler, değerler ve altta yatan varsayımların ayırt edilmesi ile mümkün olacaktır (Schein, 2002). Bu algılamaları ölçmenin bir yolu da metaforlardır.

Metafor Grekçe'de "Transfer-Taşıma" anlamına gelen metapherein kelimesinden türemiştir. Türk Dil Kurumu Türkçe sözlüğüne göre metafor kavramının karşıı̆̆ı istiaredir. İstiare; ödünç, borç ve eğreti alma, ödünçleme anlamındadır. Metafor, kullanımı sözlükte olmayan bir dil kullanmak ve karmaşık ifadelerle anlam üretmek demektir (Alpaslan, 2007: 37). Kültürel değerler için de sembolik olarak anlam iletmenin önemli bir biçimi olan metaforlar, bir fikir, obje ya da eylemi, bir sözcük veya deyim ile herhangi bir duruma benzeterek ifade etme biçimidir (Palmer ve Lundberg,1995:80). Metafor, insanın derinliklerinde yatan gerçeklerin ortaya çıkarılmasında kullanılan benzetmeler olarak da tanımlanabilmektedir. Metafor kavramı, bilinmeyeni bilinene aktarmak suretiyle açıklamak ya da nitelikleri bir gerçeklik düzleminden bir başkasına aktarmak suretiyle kullanılan bir söz ya da görüntü aracı olarak tanımlanabilir (Mutlu,1994:106).

Metaforlar, sosyal bilimlerin diğer alanları gibi örgüt ve yönetimle ilgili çözümlemelerde de yaklaşık yirmi yıldan beri üzerinde konuşulan bir konu olmuştur. Kültürü temel bir metafor olarak görmek, gerçeği açıklamada nesnellikten çok öznel, yorumsamacı ve fenomenolojik bir temele dayanmak demektir. Bu bakış açısından sosyal dünya, objektif bir gerçek olarak görülemez ve ölçülemez; elle tutulur, gözle görülür, somut bir biçimde belirlenemez. Metaforlar, insanların gerçekle ilişkilerinde önemli yer tutan araçlardır. Dolayısıyla gerçek, insanların paylaştıkları anlam ve semboller sistemi yoluyla kavranır ve yeniden üretilir (Şişman, 2011: 109110). Örgüt kültürünün metaforlarla analizinde yüzeysel, aracı ve kök metaforlar şeklinde üç düzeyli bir kavramsallaştırma tercih edilebilmektedir (Lyons, 2003'den aktaran Erdem, 2010).

Sembolik kodlara yönelik ilk çalışmalardan biri, Barley'in (1983), bir cezaevinde gözlem ve görüşmelere dayanan semiyotik veri toplama çalışmasıdır. Bech ve Moore (1984) Kanada'da bankalar üzerine yaptıkları bir çalışmada yapı, güç, statü, iletişim, örgütsel belirlilik ve firma 
imajı gibi örgütsel değişkenleri metaforlarla analiz etmişlerdir. Bates'in (1984) eğitim örgütlerine yönelik çalışmasında öğretmenlerin, idarecilerin ve öğrencilerin kişilerarası ilişkilerini, güç yapılarını tanımlamada kullandıkları metaforlara dikkat çekilmektedir. Bu farklı araştırmalarda uygulanan yöntem, metaforların gözlem ve yönlendirilmiş görüşmelerle belirlenmesidir. Kanada'da bankalar üzerinde yapılan çalışmada ise yerel dilde kullanılan güçlü metaforlardan yararlanılmıştır (Aktaran Erdem ve Şatır, 2000: 28). Erdem (2010) yüksek lisans öğrencileri üzerinde yaptığı bir çalışmada üniversiteye ilişkin kök metaforları araştırmıştır. Tamimi (2005) tekstil sektöründe örgüt kültürünü metaforlarla analiz etmeye yönelik bir çalışma yapmıştır. Bu çalışmada örgüt kültürünün boyutları örgütsel kimlik, performans-ödül ilişkisi, risk üstlenmeyi teşvik, güç mesafesi, örgütsel yapı, örgütsel iletişim metaforlarla analiz edilmiştir. Metaforların kullanımında; pozisyona, cinsiyete, hizmet süresine ve görev yapılan işletmeye göre yöneticiler ve diğer üyeler arasında farklılıklar ortaya çıkmıştır. Kadınlar erkeklere göre daha çok olumlu metafor kullanmışlardır. Hizmet süresiyle olumlu metafor kullanımı doğru orantılıdır. Evcim (2008) biri kamu diğeri özel sektörden olmak üzere iki kuruluştaki çalışanlara, örgüt kültürünün tüm boyutlarını içeren bir çalışma yapmıştır. Metafor sorularının analizinin ortaya koyduğu veriler yedi alt boyutta toplanmıştır. Bunlar çatışma, yaratıcılık, otorite, örgütsel rekabet, iletişim, güçlendirme ve örgütsel güven boyutlarıdır. Yazar bu boyutların klasik kültür ile modern kültür arasındaki yelpazenin neresinde olduğuna ve birbirleriyle nasıl bir ilişki içinde olduklarına bakmıştır. Çalışmada, örgütsel ortamın modern örgüt kültürüne klasik örgütsel yapıdan daha yakın olduğu, örgüt üyelerinin ortak deneyimlerini anlamlandırırken ortak metaforlar kullandıkları ve benzer anlamda algılandığı ortaya konulmuştur.

Bu araştırmanın amacı; bir kamu bankasında, bir yöntem olarak metafor analizi ile örgüt kültürüne ilişkin tespitlerde bulunmaktır. Örgüt kültürünün unsurlarının, örgüt çalışanlarının kullanmış olduğu metaforlarla tespit edilmesi amaçlanmıştır. Bu amaç doğrultusunda araştırmanın problem cümleleri şunlardır:

- Banka çalışanları örgüt kültürü unsurlarına ilişkin olarak hangi metaforları kullanmaktadır?

- Bu metaforların kullanılma nedenleri nelerdir?

- Bu banka için mevcut örgüt kültürüne ilişkin anlamlar nasıl yorumlanabilir?

Araştırmanın örgüt kültürünün nitel bir yöntem olarak metaforlarla analiz edilmesi, örgüt kültürüne ilişkin nicel yöntemler için yapılan "örgüt çalışanlarının önceden belirlenmiş bir yapıya maruz bırakılması, önceden belirlenmiş ve yapılandırılmış bir sınıflamanın uygulanması, karmaşık, derinlerde yer eden ve kolaylıkla tanımlanamayan, ortaya çıkarılamayan kültürel değerlerden çok, tanımlanabilir ve yüzeysel tutumlara değinebileceği ve örgüt hakkında yeterli açıklamalar sunamayacağı ya da örgüt profilini ve çalışılan gruplar arasındaki farklılıkları tekdüze bir biçimde verebileceği" (Gizir, 2003) şeklindeki eleştirileri ortadan kaldırmayı hedefleyen bir yaklaşım sunmaktadır. Araştırmanın, metafor analizinin kültüre dair sunduğu bilgiler ile bankacılık sektörü açısından kültürün tespitinde kullanılabilecek bir yöntem olarak yazına katkı sağlayacağı düşünülmektedir. Özellikle ABD’de 2007-2009 arasında yaşanan finansal kriz sonrası, bankalara olan güveni yeniden inşa etmek ve finansal dengeyi sağlamak isteği, bankalarda örgüt kültürünün tartışılmaya başlanmasına neden olmuştur. Bankalarda güçlü bir kültürün varlığı finansal sonuçları destekleyen bir olgudur (Thakor, 2016). Türkiye gibi gelişen ekonomiler için güçlü kültürler ulusal gelişme için önemli bir itici güçtür. Bunun yanı sıra bankalar açısından, finans merkezleri sayılan, rekabetin yoğun olduğu büyük şehirler yerine coğrafi olarak merkeze uzak bölgelerde kültürün nasıl şekillendiğini ortaya koyması, finans sektörü 
içinde yer alan bankaların örgüt kültürüne dair ipuçları sunması da çalışmanın diğer katkıları arasındadır.

\section{Araştırmanın Yöntemi}

\subsection{Araştırmanın Deseni}

Araştırmanın deseni nitel yöntemler içerisinde yer alan yorumsamacı olgubilim'dir (hermeneutic phenomenology). Çalışmanın olgusu örgüt kültürü ve alt boyutlarını kapsamaktadır. Bu kapsamda örgüt kültürünü incelemek üzere örnek olay kullanılmıştır. Çalışmada analiz birimi olarak bir kamu bankasının örgüt kültürü metaforlar aracılığı ile incelenmiştir.

\subsection{Araştırmanın Çalışma Grubu}

Araştırmanın çalışma gurubunu; Tokat ilinde faaliyet gösteren bir kamu bankasının şubelerinde görevli çalışanlar oluşturmaktadır. Bankanın 6 adet şubesi bulunmaktadır. Bu şubelerde; Tokat Merkez Şubesinde 18, Zile Şubesinde 12, Turhal Şubesinde 11, Niksar Şubesinde 10, Erbaa Şubesinde 9, Reşadiye Şubesinde 7 personel hizmet vermektedir. Tüm şubelerdeki toplam 67 kişi araştırma kapsamına alınmıştır. Banka'nın seçiminde nitel örneklem seçim yöntemlerinden amaçlı örnekleme yöntemi içerisinde yer alan kolay ulaşılabilir durum örneklemesi tercih edilmiştir (Yıldırım ve Şimşek, 2013: 135-142).

\subsection{Araştırmada Kullanılan Veri Toplama Aracı}

Araştırmada standartlaştırılmış görüşme formu yardımı ile veriler toplanmıştır. Araştırma verileri metaforlar aracılı̆̆ı ile elde edilmiştir. Metafor analizinde alan yazında iki farklı ölçüm yaklaşımı söz konusudur. İlk yaklaşımda katılımcılara ölçülmek istenen kavramı sunarak akıllarına gelen ilk metaforu serbest çağrışımla söylemeleri istenmektedir. Örneğin: Öğrenci sözcügü verilerek akla ilk gelen sözcük ya da deyiş kaydedilmektedir. İkinci yaklaşım ise metaforları ortaya çıkaracak ifadeleri, eylemler ya da durumlarla sormaktır. Örn. Bu kuruluşun çalışma sistemi. gibidir (Billups, 2011a). Bu çalışmada ikinci yaklaşım benimsenmiştir.

Araştırmada kullanılan veri toplama aracı iki bölümden oluşmaktadır. Birinci bölümde katılımcıların cinsiyeti, eğitim durumu, bankadaki hizmet süresi, pozisyondaki hizmet süresi sorulmuştur. Görüşme formunda kişisel bilgilerden sonra 32 adet standartlaştırılmış açık uçlu soru yer almaktadır. Araştırmada, örgüt kültürünün metaforlarla analizini gerçekleştirmek üzere hazırlanan görüşme formu, Tamimi'nin (2005) ve Evcim'in (2008) çalışmalarında kullanılan ölçekler temel alınarak geliştirilmiştir. Banka çalışanlarının, örgüt kültürünün; örgüt kimliği, performans ödül ilişkisi, risk üstlenmeyi teşvik, güç ilişkileri, personel ve iş ilişkileri, örgüt yapısı ve iletişim boyutlarında hazırlanan sorulara ilişkin düşüncelerini, metaforlarla ifade etmeleri ve nedenini açıklamaları istenmiştir. Boyutlara ilişkin detaylı unsurlar;

- Örgüt kimliği; banka, bankanın geleceği, yeni işe başlayanlar ve kurumun bir çalışanı olmak,

- Performans ödül ilişkisi; bankadaki terfi sistemi, yeni fikir ve düşüncesi olanların banka için önemi, hata yapan personelin durumu, bankadaki ödül sistemi,

- Örgütsel yapı; bankadaki kurallar, bankadaki çalışma hayatı,

- Illetişim; örgütteki bölümler arasındaki ilişkiler, bankadaki haberler, bankadaki törenler, bankanın çalışma ilkesi, personel arasındaki ilişki, bankanın tarihi, bankanın lideri, personel arasındaki bağlar, çalışanlar arasındaki dil, işe yeni başlayanlara bankayla ilgili anlatılan hikâyeler, bankanın dış çevreyle ilişkisi, bankadaki teknoloji, bankadaki kılık, kıyafet düzeni, 
- Güç ilişkisi; bankadaki yöneticilerin iş ortamındaki durumu, çalışanların banka için durumları, banka yöneticisinin iş dışındaki durumu, banka çalışanlarının yönetici açısından durumları, yöneticinin makam odası, bankadaki personelin iş ortamındaki durumu, banka çaıışanının bankadaki pozisyonu, çalışma ortamının durumu, bankanın bir çalışanı olmanın ne anlam ifade ettiği, hiyerarşik kıdemler arasındaki ilişki olarak belirlenmiştir.

Aşağıda görüşme formunda yer alan örnek bir soru yer almaktadır:

"Cümlelerde boş bırakılan yerlere sizce uygun bulduğunuz metaforu (mecazıbenzetmeyi) yazınız.

Örnek: Benim için bu bankanın geçmişi DENiZ FENERi gibidir/benzemektedir. Çünkü yol göstericidir.

Benim için bu bankanın geçmişi BALIK HAFIZASI gibidir/benzemektedir. Çünkü her şey unutulur.

"Benim için bu bankanın geçmişi (tarihi) ..................gibidir/benzemektedir. Çünkü

\subsection{Araştırmanın Geçerliliği ve Güvenilirliği}

Nitel araştırmalarda araştırmacının önyargılarından ve varsayımlarından arındııılmış verilere ulaşmak ve bu verilerin doğasına uygun bir analiz yaklaşımı benimseyerek sonuçlara ulaşmak önemlidir. Yani araştırmacı yansız bir yaklaşımla alandaki katılımcılar tarafından oluşturulmuş öznel verileri toplamalı ve analiz etmelidir (Yıldırım ve Şimşek, 2013: 307-308). Bu çalışmada, araştırmaya katılan katılımcılara araştırmayla ilgili ayrıntılı bilgi verilmiş ve gönüllü olarak görüşme sorularını cevaplamaları istenmiştir. Katılımcıların kimlik bilgilerine yer verilmemiş isim yazmamaları önemle belirtilmiştir. Katılımcıları aldatacak yanıltacak açıklamalardan, davranışlardan uzak durulmuştur. Araştırma verileri özenle toplanmış, sistematik bir şekilde analiz edilmiş ve sonuçların yazılmasında ve paylaşılmasında verilere sadık kalınarak etik ilkeler benimsenmiştir.

Nitel araştırmalarda geçerlik stratejilerinden birisi de zengin ve yoğun betimlemedir. Yazarların detaylı bir betimleme sunmaları okuyucuların bilgilere ilişkin kararını etkilemektedir (Creswell, 2016). Bu çalışmada bu strateji dikkate alınmıştır

Bunun yanı sıra geçerliliği artırmayı sağlayacak şekilde söz konusu bankanın farklı şubeleri ve farklı düzeyde çalışanları ile görüşülerek veri çeşitliği de sağlanmıştır.

Nitel araştırmacının araştırmaya iyi niyetle başlaması ve araştırmanın iyi niyetle sürdürülmesi önemlidir. İyi niyet, her ne kadar ölçülmesi zor ve tanımı kişiden kişiye farklıııklar gösterse de araştırmaya dâhil olan insanların refahı, psikolojik ve fiziksel sağlıkları, özgürlükleri, özel hayatları insani ve etik açılardan değerlendirilmeli ve araştırmacılar tarafından korunmalıdır. Bu çalışmada her aşamada etik ilkelere bağlı kalınarak çalışma hazırlanmıştır.

\subsection{Verilerin Toplanması ve Analizi}

Örgüt kültürünün boyutlarını metaforlarla tespit etmeye yönelik olarak hazırlanmış açık uçlu görüşme soruları, katılımcılar ile yüz yüze görüşülerek cevaplandırılmıştır. Bankaların bizzat ziyaret edilmesiyle, yaklaşık 30 dakikada gerçekleştirilen görüşmeler 12 haftada tamamlanmıştır. Toplanan veriler öncelikle Excel programı yardımı ile her soruyu niteleyen metafor ve açıklaması ile tablolaştırılmıştır. Elde edilen verilerin analizinde betimsel analiz ve içerik analizi kullanılmıştır. Örgüt kültürünün farklı boyutları için üretilen metaforlar ve nedenler içerik analizi ile benzerlik ve farklılıklarına göre tematik başlıklar altında toplanmıştır. . İçerik 
analizi süreci, (i) Verilerin kodlanması, (ii) Kategori oluşturma, (iii) Verilerin kodlara ve kategorilere göre düzenlenmesi, (iv) Bulguların tanımlanması ve yorumlanması şeklindedir (Yıldırım ve Şimşek, 2013). Sonrasında anlamların tasnifi ile analiz tamamlanmıştır.

\section{Araştırmanın Bulguları}

\subsection{Katılımcılara İlişkin Betimsel Bulgular}

Araştırmanın katılımcılarına ilişkin kişisel bilgiler Tablo 1'de yer almaktadır. Araştırmaya dâhil olan 67 banka çalışanının 18'i erkek, 49'u kadındır. Çalışanların \%23,9'u lise, \%67,2'si üniversite, \%9'u yüksek lisans mezunudur. Banka çalışanlarının \%4,5'i bir yıldan az bir süredir, \%38,8'i 1-5 yıl arası, \%43,3'ü 5-10 yıl arası, \%13,4'ü 10 yıldan fazla süredir şu anki iş yerinde çalışmaktadır. Katılımcıların \%19,4'ü banko asistanı, \%11,9'u operasyon asistanı, \%9'u operasyon yetkilisi, \%16,4'ü KOBi MiY yetkilisi, \%13,4'ü bireysel MiY yetkilisi, \%6'sı KOBi MiY asistanı, \%9'u müdür, \%9'u ise güvenlik görevlisidir.

Tablo 1: Araştırmaya Katılan Banka Çalışanlarının Kişisel Bilgilerine Iliş̧kin Frekans ve Yüzde

\begin{tabular}{llll} 
& \multicolumn{3}{c}{ Dağılımları } \\
\hline Kişisel Özellikler & & Frekans & Yüzde(\%) \\
\hline \hline Cinsiyet & Kadın & 49 & 73,1 \\
Eğitim Durumu & Erkek & 18 & 26,9 \\
& Lise & 16 & 23,9 \\
& Üniversite & 45 & 67,2 \\
Hizmet Süresi & Lisans Üstü & 6 & 8,9 \\
& 1 Yıldan Az & 3 & 4,5 \\
& $1-5$ Yıl & 26 & 38,8 \\
& 5-10 Yıl & 29 & 43,3 \\
Pozisyonu & 10 Yıl ve üzeri & 9 & 13,4 \\
& Banko Asistanı & 13 & 19,3 \\
& Operasyon Asistanı & 8 & 11,9 \\
& Operasyon Yetkilisi & 6 & 9,0 \\
& Kobi MiY Yetkili & 11 & 16,4 \\
& Bireysel MiY Yetkili & 9 & 13,4 \\
& Kobi MiY Asistanı & 4 & 6,0 \\
& Bireysel MiY Asistanı & 4 & 6,0 \\
& Müdür & 6 & 9,0 \\
& Güvenlik Görevlisi & 6 & 9,0 \\
\hline
\end{tabular}

\section{2. Örgüt Kültürüne İlişkin Kullanılan Metaforların Olumlu ve Olumsuz Olmasına Göre Düzenlenmesi ile Elde edilen Bulgular}

Kamu bankası çalışanlarının örgüt kültürünü nitelendirirken kullanmış oldukları metaforlar içerik analizi ile incelenerek olumlu ve olumsuz olmasına göre sınıflandırılmıştır. Katılımcılara araştırma kapsamına alınan kamu bankasının örgüt kültürüne ilişkin olarak sorulan metaforlar, örgüt kimliği, performans ödül ilişkisi, risk üstlenmeyi teşvik, güç ilişkileri, personel ve iş ilişkileri, örgüt yapısı ve iletişim açısından değerlendirilmiştir. Bazı sorulara aynı cevaplar verilebildiği için mükerrer metaforlar aynı grup içerisinde yer almaktadır.

En çok olumlu metafora sahip unsurlar sırasıyla banka çalışanlarının önemi $(\% 98,5)$, bankanın geçmişi (\%94), kılık/kıyafet düzeni (\%91), liderin konumu ile yeni fikri olanlar $(\% 89,6)$, bankanın geleceği $(\% 86,6)$, personel arasındaki ilişki $(\% 86,6)$, kurumun çalışanı olmak $(\% 86,6)$, dış çevreyle ilişkisi $(\% 85,1)$, bankanın konumu ve terfi sistemi $(\% 85,1)$, personel arasındaki bağ $(\% 83,6)$, personelin işteki tutumu $(\% 80,6)$, dil $(\% 79,1)$, pozisyon durumu $(\% 79,1)$, çalışma 
ilkesi $(\% 79,1)$, törenler, iş dışında yönetici tutumu, makam odası $(77,6)$, bankadaki haberler $(\% 73,1)$, teknoloji, bölümler arası ilişki $(\% 67,2)$, yöneticinin tavrı, çalışma ortamı $(\% 65,7)$, ödül sistemi $(\% 59,7)$, çalışma hayatı $(\% 56,7)$, personelin yöneticiler için durumu $(\% 53,7)$ olmuştur. En çok olumsuz metafora sahip unsurlar ise hata yapan personel $(\% 88,1)$, hiyerarşik kıdemler arasındaki ilişki $(\% 77,6)$, anlatılan hikâyeler $(\% 70,1)$, yeni işe başlayanların durumu $(\% 61,2)$ ve kurallar $(\% 50,7)$ olmuştur.

\section{3. Örgüt Kültürünün Metaforlarla Analizine iliş̧kin Bulgular}

\subsection{1.Örgüt Kimliği}

Çalışmada örgüt kimliğine ilişkin metaforları analiz etmek amacıyla "Benim için bu banka......gibidir/benzemektedir. Çünkü......” sorusuna verilen cevaplar analiz edilmiştir. Analiz sonucunda metaforlar ve anlamlarına ilişkin bulgular Tablo 2' de yer almaktadır. Genel olarak banka çalışanları, çalıştıkları örgütü güven duyulan, aile gibi sıcak, korunaklı, büyük ve büyümekte olan bir kuruluş olarak nitelendirmişlerdir. Bankaya ilişkin uğraşı alanı nedeniyle bazı olumsuz anlamlar da yüklenmektedir.

Tablo 2: Katılımcıların Bankaya ilişkin Kullandıkları Metaforlar ve Analiz Bulguları

\begin{tabular}{|c|c|c|}
\hline $\begin{array}{l}\text { Benim için bu ban- } \\
\text { ka......gibidir/benzemektedir }\end{array}$ & Metaforlar & Anlam/Analiz \\
\hline & $\begin{array}{l}\text { Güneş, ışık, ampul, pusula, } \\
\text { kutup yıldızı, yol, deniz, } \\
\text { kitap, profesör, devlet }\end{array}$ & $\begin{array}{l}\text { Etrafını aydınlatan, müşterileri ve } \\
\text { çalışanları için yol gösterici, büyük ve } \\
\text { büyümeye devam eden. }\end{array}$ \\
\hline & $\begin{array}{l}\text { Ekmek, su, nefes, yaşam, } \\
\text { aile, ev geniş aile, sığınacak } \\
\text { liman }\end{array}$ & $\begin{array}{l}\text { İlişkilerin sıcak olduğu, bağlı oldukları, } \\
\text { korunma hissettikleri olmazsa olmaz } \\
\text { temel ihtiyaç. }\end{array}$ \\
\hline & $\begin{array}{l}\text { Amerika, tefeci, vampir, } \\
\text { mafya, sabır taşı, bukale- } \\
\text { mun }\end{array}$ & $\begin{array}{l}\text { Sömüren, faiz alan, borcunuzu öde- } \\
\text { mediğinizde sonunuzun kötü olduğu, } \\
\text { sabretmeyi burada öğrendiğiniz, } \\
\text { duruma göre değişen. }\end{array}$ \\
\hline & $\begin{array}{l}\text { Elektrik süpürgesi, doktor, } \\
\text { kıvılcım, balçıkla sıvanan } \\
\text { güneş, İstanbul İstiklal } \\
\text { Caddesi, mağaza, dev }\end{array}$ & $\begin{array}{l}\text { Müşteri çeken ve müşteriye çözüm } \\
\text { üreten, parayla uğraşıldığı için her an } \\
\text { her şeyin olabileceği, çok yoğun çalışı- } \\
\text { lan, istediğiniz her şeyi bulabileceğiniz } \\
\text { geniş ve büyük bir yer. }\end{array}$ \\
\hline
\end{tabular}

Çalışmada örgüt kimliği için kullanılan metaforları analiz etmek amacıyla "Bankanın geçmişi (tarihi) ........ gibidir/benzemektedir. Çünkü......" sorusuna verilen cevaplar analiz edilmiştir (Tablo 3). Çalışanlar bankalarının dikilmiş bir ağaç gibi gün geçtikçe geliştiğini ve kök saldığını düşünmektedir. Bankanın geçmişine saygı duyulmaktadır. Bankanın gelecekte de başarılı bir kuruluş olmaya devam edeceği algısını taşımaktadırlar. 
Tablo 3: Katılımcıların Bankanın tarihine Iliş̧kin Kullandıkları Metaforlar ve Analiz Bulguları

\begin{tabular}{|c|c|c|}
\hline $\begin{array}{l}\text { Bankanın geçmişi (tarihi) ......... } \\
\text { gibidir /Benzemektedir }\end{array}$ & Metafor & Anlam/Analiz \\
\hline & $\begin{array}{l}\text { Çınar ağacı, ağaç kökü, kavak } \\
\text { ağacı }\end{array}$ & $\begin{array}{l}\text { Bir ağaç gibi günden güne gelişen ve kök } \\
\text { salan }\end{array}$ \\
\hline & Volkan, deniz altı, okyanus & Derin bir geçmişi olan \\
\hline & $\begin{array}{l}\text { Osmanlı Devleti, antika, } \\
\text { destan, müze, yıllanmış şarap, } \\
\text { konak, karga, eski marka } \\
\text { telefonlar, Türkiye, Türkiye } \\
\text { tarihi, Kurtuluş Savaşı, roman, } \\
\text { kitap, bayrak, ansiklopedi, } \\
\text { ordu, devlet }\end{array}$ & $\begin{array}{l}\text { Tarihinin çok eski olduğunu düşünmekte- } \\
\text { ler, çalıştıkları kuruluşun gelecekte de } \\
\text { başarılı olacağına inanç duymaktalar }\end{array}$ \\
\hline & $\begin{array}{l}\text { Beyaz sayfa, deniz feneri, Bolu } \\
\text { tüneli, temiz sayfa, el feneri, } \\
\text { berrak su, ışık, güneş }\end{array}$ & $\begin{array}{l}\text { Tarihinin bankanın geleceğini aydınlataca- } \\
\text { ğı düşüncesi }\end{array}$ \\
\hline & Can simidi & $\begin{array}{l}\text { Geleceğine yardımcı olacak bir tarihe } \\
\text { sahip }\end{array}$ \\
\hline
\end{tabular}

Çalışmada örgüt kimliğine ilişkin metaforları analiz etmek amacıyla "Bankanın geleceği............gibidir/benzemektedir. Çünkü......" sorusuna verilen cevaplar analiz edilmiştir (Tablo 4). Metaforlar çalışanların gelecekte bankanın sağlam temeller üzerinde güçlenerek gelişeceğini ve etki alanının genişleyeceğini belirtmektedir. Bankada zaman içinde olumlu gelişmelerin yaşanacağına inanılmaktadır. Çalışanlar bankanın geleceğinin aydınlık ve güzel olacağını düşünmektedirler. Sağlam bir banka olduğunu hatta büyüyen yapısı nedeniyle dışarıdan zarar verilebileceğini ifade etmektedirler.

Tablo 4: Katılımcıların Bankanın Geleceğine Ilişkin Kullandıkları Metaforlar ve Analiz Bulguları

\section{Bankanın geleceği.............gibidir/}

benzemektedir.
Metafor

Binalar, deniz, geniş ve uzun yol, ağaç, demir,

Kaya, dağlar, devlet

Bebek, öğrenci

Fırından çıkmış poğaça

Jeneratör, avize

Tünel, ufuk çizgisi

Yılan, otoban

Doğal su kaynağı, sonsuz yol

Siyah

Taşlanan elma ağacı

\section{Anlam/Analiz}

Bankanın gelecekte sağlam temeller üzerinde güçlenerek gelişeceği

Büyüyeceği ve zaman içinde gelişeceği

Büyüyerek yeni şubeler açacağ

Önce kendisine sonra etrafına faydalı olacağı

Ucunda ışık olduğu Kendini yenilediği

Hiç bitmeyen bir sektör olduğu

Her şeyin olumsuz olduğu

İyi bir geleceği olduğu için kötüleneceği ve zarar verileceği 
Çalışmada örgüt kimliğine ilişkin metaforları analiz etmek amacıyla "Bankada yeni işe başlayanlar ........gibidir/benzemektedir. Çünkü......" sorusuna verilen cevaplar analiz edilmiştir (Tablo 5). Çalışanların, bankada işe yeni başladıklarında karşılaştıkları durumlar yani kültürün tarihi unsuru burada önem kazanmaktadır. Çünkü bankada sadece yeni işe başlayanların durumu değil daha önceden işe başlayanların durumu da metaforlarla nitelendirilmiştir. Örgüt geçmişinin yeni gelenlere aktarılması açısından da metaforlar aracılık yapmaktadır.

Tablo 5: Katılımcıların Bankada Yeni Iş̧e Başlayanlara iliş̧kin Kullandıkları Metaforlar ve Analiz Bulguları

\begin{tabular}{|c|c|c|}
\hline $\begin{array}{l}\text { Bankada yeni işe başlayanlar } \\
\text {........gibidir/benzemektedir }\end{array}$ & Metafor & Anlam/Analiz \\
\hline & $\begin{array}{l}\text { Acemi çırak, çaylak, yeni } \\
\text { asker, olgunlaşmamış meyve, } \\
\text { sazan balığı, sudan çıkmış } \\
\text { balık, şaşkın ördek, bebek, tek } \\
\text { farı sönmüş araba, fidan, işçi } \\
\text { arı, yavru aslan, meyvesiz } \\
\text { ağaç, tohum }\end{array}$ & $\begin{array}{l}\text { Yeni işe başlayanların tecrübesiz ve hata } \\
\text { yapma ihtimallerinin yüksek olduğu, } \\
\text { sürekli kontrol edilmeleri gerektiği ama } \\
\text { iyi bir yönlendirmeyle başarılı olacakları }\end{array}$ \\
\hline & Atmaca, aç kurt, sincap & $\begin{array}{l}\text { Kendilerini üstlerine ispat etmek, kabul } \\
\text { görmek için gerekli gereksiz her konu- } \\
\text { nun içinde yer aldıkları }\end{array}$ \\
\hline & Kuş, tavşan, civciv, kuzu & $\begin{array}{l}\text { Yeni girdikleri ortamda ürkek tavırlar } \\
\text { sergiledikleri }\end{array}$ \\
\hline
\end{tabular}

Çalışmada örgüt kimliğine ilişkin metaforları analiz etmek amacıyla "Bu kuruluşun bir çalışanı olmak ........gibidir/benzemektedir. Çünkü......" sorusuna verilen cevaplar analiz edilmiştir (Tablo 6). Çalışanların kullanmış olduğu çoğu metafor banka çalışanlarının görev yaptığı bankaya kendilerini yakın ve ait hissettikleri hatta bankanın ayrılmaz parçası olarak kendilerini gördüklerini ortaya koymaktadır. Gurur verici bir o kadarda zor olan bir iş yaptıklarını ifade etmekte, kendilerini diğerlerinden farklı ve ayrıcalıklı görmektedirler.

Tablo 6: Katılımcıların Bu Kuruluşun Bir Çalışanı Olmak Konusunda Kullandıkları Metaforlar ve Analiz Bulguları

Bu kuruluşun bir çalışanı olmak ........gibidir/benzemektedir
Metafor
Anlam/Analiz

\section{Aile üyesi, halka, el-ayak, kart, bir ağacın dalı, testere dişi, nefes, böbrek, yapbozun bir parçası, su, parmak, vagon, anahtar, çocuk Altın, elmas, gül, yıldız, inci, mercan, milletvekili, hazine, pırlanta}

Mor inek, güvercin, bakan, milletvekili, şehit olmak

Doktor

Anahtar

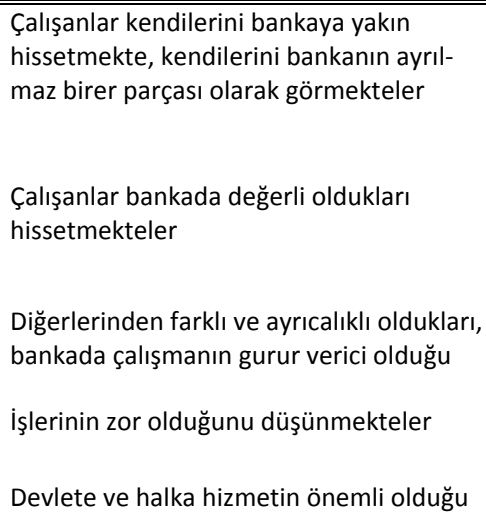
hissetmekte, kendilerini bankanın ayrılmaz birer parçası olarak görmekteler

Çalışanlar bankada değerli oldukları hissetmekteler

Diğerlerinden farklı ve ayrıcalıklı oldukları, bankada çalışmanın gurur verici olduğu

İşlerinin zor olduğunu düşünmekteler Devlete ve halka hizmetin önemli olduğu 


\subsubsection{Performans Ödül iliş̧kisi}

Çalışmada örgüt kültürünü yansıtan bir unsur da performans ödül ilişkisidir. Bu konuda kullanılan metaforları analiz etmek amacıyla "Bankadaki terfi sistemi ........gibidir/benzemektedir. Çünkü......" sorusuna verilen cevaplar analiz edilmiştir. Analiz sonucunda metaforlar ve anlamlarına ilişkin bulgular Tablo 7'de yer almaktadır. Banka çalışanları, terfi sisteminin performansa dayalı olarak gerçekleştiğini, yöneticilerin terfi sürecinde adil davrandıklarını ancak bir üst kademeye geçişin disiplin ve çalışma gerektiren zor bir süreç olduğunu ifade etmektedir.

Tablo 7: Katılımcıların Bankadaki Terfi Sistemine Ilişkin Kullandıkları Metaforlar ve Analiz Bulguları

\begin{tabular}{|c|c|c|}
\hline $\begin{array}{l}\text { Bankadaki terfi sistemi } \\
\text {........gibidir/benzemektedir }\end{array}$ & Metafor & Anlam/Analiz \\
\hline & $\begin{array}{l}\text { Merdiven, asansör, basamak, } \\
\text { sınıf geçme, gökdelenin } \\
\text { katları, bal, meyve, yemek } \\
\text { yemek, kule, seyahat, büyü- } \\
\text { yen bir çocuk, } \\
\text { Piyango, loto, dönme dolap, } \\
\text { boş bardak, kuş }\end{array}$ & $\begin{array}{l}\text { Terfi sisteminin kademeli ve zaman } \\
\text { içerisinde performansa dayalı olarak } \\
\text { yönetici tarafından adil olarak işletildiği }\end{array}$ \\
\hline & Askeri sistem & Disiplin ve emek istediği \\
\hline & Barut, yürüyen çocuk & Kendi çabanız ile yükseleceğiniz \\
\hline & Koltuk değneği & İlerlemek için desteğe ihtiyaç olduğu \\
\hline & Elektrik direğine tırmanmak & Yükselmenin riskli olduğu \\
\hline & Karlı dağ, sınıf geçme & Terfi sisteminin zor olduğu \\
\hline
\end{tabular}

Çalışmada performans ödül ilişkisinde kullanılan metaforları analiz etmek amacıyla "Bankadaki ödül sistemi ........gibidir/benzemektedir. Çünkü......" sorusuna verilen cevaplar analiz edilmiştir (Tablo 8). Analiz sonucunda banka çalışanlarının ödüllendirildiklerinde mutlu oldukları, ödüllerin kendilerini motive ettiği ancak ödüllerin yeterli sıklıkta verilmediği, ödül sisteminde kriterler ve standartların eksik olduğu gözlenmektedir.

Tablo 8: Katılımcıların Bankadaki Ödül Sistemine Ilişkin Kullandıkları Metaforlar ve Analiz Bulguları

\begin{tabular}{|c|c|c|}
\hline $\begin{array}{l}\text { Bankadaki ödül sistemi } \\
\text {........gibidir/benzemektedir }\end{array}$ & Metafor & Anlam/Analiz \\
\hline & $\begin{array}{l}\text { Piyango, rüya, mucize, boş } \\
\text { bardak, güvercin, yolda para } \\
\text { bulmak, loto, hayal, sürpriz } \\
\text { yumurta }\end{array}$ & $\begin{array}{l}\text { Bankadaki ödül sisteminin alınabilmesi } \\
\text { şans eseri gibi görülmekte }\end{array}$ \\
\hline & $\begin{array}{l}\text { Sadaka, sabun, düşük banket, } \\
\text { asgari ücret, öğrenci harçlığı, } \\
\text { erimiş kaşar, pembe dizi, } \\
\text { kurumaya yüz tutmuş akarsu, } \\
\text { sıra beklemek, çatalla su } \\
\text { içmek, ağustos ayında kar } \\
\text { yağmak, fotoğraf, Everest dağı }\end{array}$ & $\begin{array}{l}\text { Ödüllerin yeterli sıklıkta verilmediği, } \\
\text { hatta alınmasının zor olduğu, miktarının } \\
\text { da az olduğu }\end{array}$ \\
\hline & Klima, döviz, hazine, mevsim & $\begin{array}{l}\text { Ne kadar alınacağının belli olmadığı, artıp } \\
\text { azalabileceği }\end{array}$ \\
\hline & $\begin{array}{l}\text { Kırbaç performans, hediye, } \\
\text { klasik koşullanma, madalya, } \\
\text { pense, yarış }\end{array}$ & $\begin{array}{l}\text { Ödül sisteminin kendilerini motive ettiği } \\
\text { ve hızlandırdığı }\end{array}$ \\
\hline & $\begin{array}{l}\text { Ay, kaymak, şeker, oyuncak, } \\
\text { bayram, çocuğa verilen şeker }\end{array}$ & Alınan ödüllerin kendilerini mutlu ettiği \\
\hline
\end{tabular}




\subsubsection{Risk Üstlenmeyi Teşvik}

Katılımcılara, özellikle yenilikçilik açısından önem taşıyan risk üstlenmeyi teşvik konusunda sorular sorulmuştur. Risk üstlenmeyi teşvikte kullanılan metaforları analiz etmek amacıyla "Bankada yeni fikir ve düşüncesi olanlar........gibidir/benzemektedir. Çünkü......" sorusuna verilen cevaplar analiz edilmiştir. Analiz sonucunda metaforlar ve anlamlarına ilişkin bulgular Tablo 9'da yer almaktadır. Analiz bulguları bankada yeni fikir ve düşüncelerin önemli olduğu ve değer verildiğini göstermektedir. Ancak banka içerisinde yeni fikir ve düşüncesi olanlar arkadaşlarınca çok fazla desteklenmemektedir. Örgüt yeniliklere açık olsa da çalışanların bu konuda açık olmadığını, yeni fikri olanların az sayıda olduğunu anlamak açısından kullanılan metaforlar çarpıcıdır.

Tablo 9: Katılımcıların Bankada Yeni Fikir ve Düşüncesi Olanlara iliş̧kin Kullandıkları Metaforlar ve Analiz Bulguları

\begin{tabular}{|c|c|c|}
\hline $\begin{array}{l}\text { Bankada yeni fikir ve düşüncesi olan- } \\
\text { lar........gibidir/benzemektedir }\end{array}$ & Metafor & Anlam/Analiz \\
\hline & $\begin{array}{l}\text { Atatürk, bilim adamı, } \\
\text { profesör, filozof, beyin, akıl } \\
\text { küpü, öğretmen, kartal }\end{array}$ & $\begin{array}{l}\text { Yeni fikir ve düşünceye önem verildiği } \\
\text { ve değerli olduğu }\end{array}$ \\
\hline & $\begin{array}{l}\text { Maden, kardelen, pırlanta, } \\
\text { cevher, ışık, yıldız, ay, } \\
\text { kapalı kutu, ışık huzmesi, } \\
\text { ilaç }\end{array}$ & $\begin{array}{l}\text { Yeni fikir ve düşüncelerin işlenerek } \\
\text { değerli hale getirildiği }\end{array}$ \\
\hline & $\begin{array}{l}\text { Meyve veren ağaç, kayna- } \\
\text { na, ağa düşmüş balık, inek }\end{array}$ & $\begin{array}{l}\text { Yeni fikir ve düşüncesi olanların diğer } \\
\text { çalışanlarca istenmediği, dışlandığı }\end{array}$ \\
\hline & Mimar, girişimci, gazeteci & Kendilerine yeni işler inşa ettikleri \\
\hline
\end{tabular}

Çalışmada performans ödül ilişkisinde kullanılan metaforları analiz etmek amacıyla "Bankada hata yapan personel........gibidir/benzemektedir. Çünkü......" sorusuna verilen cevaplar analiz edilmiştir (Tablo 10).

Hatalar hemen fark edilmekte hata yapanlar kendilerini suçlu hissettiğinden dolayı genel olarak sessiz, ürkek bir tavır sergilemekte ve utanmaktadırlar. Hata yapanlar, yönetim ve diğerleri tarafından olumsuz görülmektedir. Banka kültüründe mükemmeliyetçiliğin olduğu ve hataya tahammül edilmediği, hatta hatalardan öğrenmenin de pek mümkün olmadığı gözlenmektedir. 
Tablo 10: Katılımcıların Bankada Hata Yapan Personele iliş̧kin Kullandıkları Metaforlar ve Analiz Bulguları

\begin{tabular}{|c|c|c|}
\hline $\begin{array}{l}\text { Bankada hata yapan perso- } \\
\text { nel........gibidir/benzemektedir }\end{array}$ & Metafor & Anlam/Analiz \\
\hline & $\begin{array}{l}\text { Süt dökmüş kedi, tavşan, } \\
\text { kalfa, yaramaz çocuk, } \\
\text { acemi şoför, vazo düşüren } \\
\text { çocuk, cam kıran çocuk, } \\
\text { deve kuşu }\end{array}$ & $\begin{array}{l}\text { Hatanın hemen fark edildiği, hata yapan- } \\
\text { ların kendilerini suçlu hissettikleri }\end{array}$ \\
\hline & $\begin{array}{l}\text { Pirinçten çıkan taş, bozuk } \\
\text { para, arızalı telefon, } \\
\text { vakitsiz öten horoz, } \\
\text { kırmızı ışı ihlali, bozuk } \\
\text { plak, bitik pil, hasta, siren } \\
\text { sesi, yanlış evlilik }\end{array}$ & $\begin{array}{l}\text { Düzgün işleyen bir sistemdeki bozuk } \\
\text { aksanlar olarak görüldükleri }\end{array}$ \\
\hline & $\begin{array}{l}\text { Günah keçisi, böcek, } \\
\text { çamur, kayan yıldız, kırık } \\
\text { cam }\end{array}$ & $\begin{array}{l}\text { Hatanın dönüşünün olmaması, hata } \\
\text { yapan kişinin hep olumsuz görüldüğü }\end{array}$ \\
\hline & $\begin{array}{l}\text { Mahkûm, dilenci, paspas, } \\
\text { çimen }\end{array}$ & $\begin{array}{l}\text { Hatanın telafisinin zor olduğu, hata yapa- } \\
\text { nın ezildiği ve cezalandırıldığı }\end{array}$ \\
\hline & Çorbanın tuzu & Hataların önemi ve olmazsa olmazlığı \\
\hline
\end{tabular}

\subsubsection{Güç iliş̧kileri}

Çalışmada güç ilişkileri için kullanılan metaforları analiz etmek amacıyla "Bankanın lideri ........gibidir/benzemektedir. Çünkü......" sorusuna verilen cevaplar analiz edilmiştir. Analiz sonucunda metaforlar ve anlamlarına ilişkin bulgular Tablo11'de yer almaktadır.

Çalışanlar, banka liderinin sorumluluklarının büyük olduğunu ve çalışanları yönettiğini, daha çok ileriyi gören, her konuda fikri olan, çalışanları yönlendiren çalışanlar için tüm sorumluluğun ve yönetimin merkezi olduğunu belirtmektedirler. Banka lideri için, hükmedici, her şeyin ondan sorulduğu, güçlü ve kibirli olduğu, her şeyin onun elinde olduğu ve gücü ifade ettiği belirtilmektedir. Öte yandan vazgeçilmez ve banka için katkıları olduğu ifade edilmekte ve her tehlikede çalışanları koruyup kolladığına inanılmaktadır.

Tablo 11: Katılımcıların Bankanın liderine Iliş̧kin Kullandıkları Metaforlar ve Analiz Bulguları

Metafor

Atatürk, başkan, Komutan, teknik direktör, yönetmen, antrenör

Atatürk, navigasyon, google arama motoru

Başbakan, kral, padişah, aslan, imparator

Anıt, kalp, kahraman

Kurt, kontrol kalemi

\section{Anlam/Analiz}

Banka liderinin sorumluluklarının büyük olduğu ve çalışanları yönettiği

Yol gösteren, daha çok ileriyi gören her konuda fikri olan ve çalışanları yönlendiren

Hükmedici, her şeyin ondan sorulduğu, güçlü ve kibirli olduğu, gücü elinde bulundurduğu

Vazgeçilmez ve banka için katkıları olduğu Her tehlikede çalışanları kollayıp, koruduğu inancı 
Çalışmada güç ilişkisinde kullanılan metaforları analiz etmek amacıyla "Bankadaki yöneticiler iş ortamında .........gibidir/benzemektedir. Çünkü......" sorusuna verilen cevaplar analiz edilmiştir (Tablo 12).

Tablo 12: Katılımcıların Yöneticilerin iş Ortamındaki Davranışlarına ilişkin Kullandıkları Metaforlar ve Analiz Bulguları

\begin{tabular}{lll}
\hline $\begin{array}{l}\text { Bankadaki yöneticiler iş ortamın- } \\
\text { da........gibidir/benzemektedir }\end{array}$ & Metafor & Anlam/Analiz \\
\hline \hline & $\begin{array}{l}\text { Baba, ağabey, aslan, arkadaş, et- } \\
\text { tırnak, su kaynağı, nar kabuğu, }\end{array}$ & $\begin{array}{l}\text { Koruyucu, kollayıcı, ellerindeki } \\
\text { yetkiyi banka çıkarları için }\end{array}$ \\
& $\begin{array}{l}\text { zincir halkası, beyin, makine, } \\
\text { ansiklopedi }\end{array}$ & $\begin{array}{l}\text { kullanan, iyi yönetim kabiliyeti } \\
\text { ile güçlü bir imaj çizen ve çalı- }\end{array}$ \\
& $\begin{array}{l}\text { Siktatör, mahkeme duvarı, bir arada tutan } \\
\text { patron, okul müdür, avcı, akba- } \\
\text { ba, çakal, cellat, maske }\end{array}$ & $\begin{array}{l}\text { Cezalandırıcı, katı ve çok samimi } \\
\text { olmadıkları }\end{array}$ \\
& İmam, kral & Kendi bildiğini okuyan \\
Vali, komutan, taş, robot & Resmi ve sert \\
\hline
\end{tabular}

Banka çalışanları, yöneticilerin iş ortamındaki davranışlarının koruyucu, kollayıcı ve düzeltici olduğunu, ellerindeki yetkiyi bankanın çıkarları doğrultusunda kullandıklarını, iyi yönetim kabiliyeti ile güçlü bir imaj çizdiklerini ve çalışanlarını bir arada tutmaya çalıştıklarını düşünmektedirler. Çalışanlarını çocukları gibi görüp onlara yeri gelince kızdıklarını, ciddi olduklarını ve disiplinli davrandıklarını da belirtmektedirler. Yöneticilerin daha çok resmi, sert ve cezalandırıcı oldukları düşünülmektedir.

Çalışmada güç ilişkisinde kullanılan metaforları analiz etmek amacıyla "Çalışanlar (personel) bankanın........gibidir/benzemektedir. Çünkü......" sorusuna verilen cevaplar analiz edilmiştir (Tablo 13). Çalışanlar kendilerini bankanın olmazsa olmaz unsurları olarak değerlendirmektedirler. Sürekli başkalarının gözetiminde çalıştıklarını ifade etmeleri kendilerini güçlendirilmiş hissetmediklerini göstermektedir. Bankanın çalışanları ile kendisini müşterilerine sunduğu ve çalışanların "vitrinde" olduğu vurgulanmaktadır. Bu yüzden çalışanların güler yüzlü, iyi giyimli olmaları ve dış görünüşlerine önem vermeleri gerektiği ifade edilmektedir. Tüm bu analizler sonrasında, banka çalışanı olmanın bireyi metalaştırdığı, duygudan uzak ve mekanik yapısına dair bulgular çarpıcıdır.

Tablo 13: Katılımcıların Banka İçin Anlamına ilişskin Kullandıkları Metaforlar ve Analiz Bulguları

\begin{tabular}{lll}
$\begin{array}{l}\text { Çalışanlar (personel) banka- } \\
\text { nın........gibidir/benzemekted } \\
\text { ir }\end{array}$ & Metafor & Anlam/Analiz \\
\hline \hline & $\begin{array}{l}\text { Çocukları, demirbaşı, organları, eli } \\
\text { ayağı, evladı, evin tuğlası, kalbi, lokomo- } \\
\text { tifi, aküsü, temeli, peteği, mücevheri, } \\
\text { anahtarı, atardamarı } \\
\text { Vitrin, ayna, gülen yüz, enstrüman, } \\
\text { çiçek, döşeme, imaj, kapı, ışık, karınca, } \\
\text { mıknatıs }\end{array}$ & $\begin{array}{l}\text { Çalışanlar kendilerini bankanın asli unsuru } \\
\text { olarmekte }\end{array}$ \\
& $\begin{array}{l}\text { Müşterileri için bankayı yansıtan börevi gören, sahnenin görünen } \\
\text { kısmında yer alan kişiler olarak güler }\end{array}$ \\
& Robot, asker, kumanda, çark, piyon & $\begin{array}{l}\text { yüzlü ve iyi giyimli olmaları gerektiği } \\
\text { düncesi }\end{array}$ \\
& $\begin{array}{l}\text { Sürekli başkasının gözetiminde çalışmaları } \\
\text { anahtar, çelik kapı, mutfak aletleri }\end{array}$ & $\begin{array}{l}\text { Bankanın çalışanlara sürekli ihtiyaç duy- } \\
\text { duğu, her çalışanın kendisine has görevi } \\
\text { ve özelliği olduğu }\end{array}$
\end{tabular}


Çalışmada güç ilişkisinde kullanılan metaforları analiz etmek amacıyla "Banka yöneticileri iş dışında ........gibidir/benzemektedir. Çünkü......" sorusuna verilen cevaplar analiz edilmiştir (Tablo 14).Banka çalışanları, yöneticilerin iş dışında; işin verdiği stresten uzaklaştıklarını ve daha samimi, daha cana yakın, esprili tavırlar sergilediklerini, ayrıca yöneticilerin, personelin sıkıntılarını dinleyip kimseyle paylaşmadıklarını, sorunlarını çözmeye çalıştıklarını ifade etmektedirler. Bazı durumlarda ise liderlerin samimiyetten uzak, duruma göre davrandıkları ve ilgili olmadıkları belirtilmektedir.

Çalışmada güç ilişkisinde kullanılan metaforları analiz etmek amacıyla "Banka personelinin yöneticiler için durumu........gibidir/benzemektedir. Çünkü......" sorusuna verilen cevaplar analiz edilmiştir (Tablo 15). Banka yöneticilerinin, banka personelini sürekli çalışan, üreten ve değerli, asli unsur olarak gördüğü düşünülmektedir. Çok çalışmak bir yandan iyi algılamalara sebep olsa da ek bir getirisinin olmadığı, çalışanların kullanıldığı ve yine kendilerini meta gibi hissettikleri olumsuz algılamalar da mevcuttur. Bu analiz ödüller konusundaki yetersizliğe dair bulguları destekler niteliktedir. Yöneticiler için işyerinde hissedilen hükmedici ve katı algılamaların karşılığı olan bulgular burada da gözlenmektedir.

Tablo 14: Katılımcıların Banka Yöneticilerinin Iş̧ Dışındaki Durumlarına ilişkin Kullandıkları Metaforlar ve Analiz Bulguları

\begin{tabular}{|c|c|c|}
\hline $\begin{array}{l}\text { Banka yöneticileri iş dışın- } \\
\text { da.........gibidir/benzemektedir }\end{array}$ & Metafor & Anlam/Analiz \\
\hline & $\begin{array}{l}\text { Arkadaş, ağabey, aile, anne baba, } \\
\text { bal, pamuk, lokum, melek, illkba- } \\
\text { har rüzgarı, eşofman, komedyen, } \\
\text { palyaço }\end{array}$ & $\begin{array}{l}\text { Yöneticilerin işin verdiği stresten } \\
\text { uzaklaştıklarında daha samimi, cana } \\
\text { yakın, esprili tavırlar sergiledikleri }\end{array}$ \\
\hline & Sır küpü, sırdaş & $\begin{array}{l}\text { Personelin sıkıntılarını dinleyip kim- } \\
\text { seyle paylaşmadıkları ve sır sakladıkla- } \\
\text { rı }\end{array}$ \\
\hline & $\begin{array}{l}\text { Ayrık küme, limonata, kafesteki } \\
\text { aslan, aktör, ikiyüzlü, çavuş, yağ- } \\
\text { danlık }\end{array}$ & $\begin{array}{l}\text { Samimiyetten uzak duruma göre tavır } \\
\text { aldıkları }\end{array}$ \\
\hline & Logo & Her duruma uyum sağladıkları \\
\hline & Ayaklı cenaze, uyurgezer, yabancı & İş dışında da çok fazla ilgili olmadıkları \\
\hline
\end{tabular}

Tablo 15: Katılımcıların Banka Personelinin Yöneticiler Iç̧in Anlamına ilişskin Kullandıkları Metaforlar ve Analiz Bulguları

Banka personelinin yöneticiler için durumu.........gibidir/benzemektedir
Metafor

Karınca, işçi arı, velinimet, eli ayağı, gözü kulağı, çocukları, mutfak eşyası, ustanın tamir takımları, tuz, nefes, oğul, masanın ayağı

Emir kulu, kiralık araba, döviz, kukla, köpek, kurt, asker

Eşya

Yoğrulmaya hazır hamur

\section{Anlam/Analiz}

Banka personeli sürekli çalışan, üreten, değerli, olmazsa olmaz olarak görülmekte

Çok çalışmanın ek bir getirisi olmadığı için "kullanılmak" gibi olumsuz algılar mevcut Çalışanların sürekli kullanıldığı Hemen şekillenebilecekleri 
Çalışmada güç ilişkisinde kullanılan metaforları analiz etmek amacıyla "Yöneticilerin makam odası ........gibidir/benzemektedir. Çünkü......" sorusuna verilen cevaplar analiz edilmiştir (Tablo 16). Banka çalışanları yöneticilerin makam odasını işle ilgili çok önemli kişilerin konuk edildiği, kararların alındığı gösterişli mekanlar olarak görmekte, makamın verdiği yetkinin etkisiyle birlikte odaya gücü simgeleyen anlamlar yüklemektedirler. Yöneticiler makam odalarında kendilerinin önemli olduklarını hissetmekte, güçlerini buradan almakta ve kendilerini ulaşıımaz ve önemli görmektedirler. Ayrıca çalışanlar yöneticilerin makam odasını bankanın dışa açılan bir kapısı olarak nitelendirmektedirler.

Tablo 16: Katılımcıların Yöneticinin Makam Odasına ilişkin Kullandıkları Metaforlar ve Analiz Bulguları

\begin{tabular}{lll}
\hline $\begin{array}{l}\text { Yöneticilerin makam odası } \\
\text {.......gibidir/benzemektedir }\end{array}$ & Metafor & Anlam/Analiz \\
\hline & $\begin{array}{l}\text { Saray, kral dairesi, makam odası, } \\
\text { köşk, süit oda, kokpit }\end{array}$ & $\begin{array}{l}\text { İşle ilgili önemli kişilerin konuk edildiği } \\
\text { gösterişli mekânlar }\end{array}$ \\
$\begin{array}{l}\text { Osmanlı Devleti, Eiffel Kulesi, Beyaz } \\
\text { Köşk, stadın locası, şato, bayrak, } \\
\text { mühür, son model araba, kale, } \\
\text { meclis, klima, göz, avize }\end{array}$ & $\begin{array}{l}\text { Odanın gücü simgelediği, yöneticilerin } \\
\text { kendilerini önemli ve ulaşılmaz hisset- } \\
\text { tikleri, güçlerini buradan aldıkları, } \\
\text { odanın gösterişli olduğu }\end{array}$ \\
& $\begin{array}{l}\text { Yol geçen hanı, müstakil ev, pazar, } \\
\text { olay yeri, akvaryum, tatlıcı } \\
\text { Cetvel, giysi dolabı, toplantı odası }\end{array}$ & $\begin{array}{l}\text { Her türlü müşterinin girebildiği ve } \\
\text { müşteri çeşitliliğinin bol olduğu bir yer }\end{array}$ \\
& Karar alınan ve düzenli bir yer olduğu \\
\hline
\end{tabular}

\subsubsection{Personel ve İş ilişkileri}

Çalışmada personelin kendisi, iş ve iş ortamına dair kullandıkları metaforlar sorulmuştur. Bu amaçla öncelikle "Bankadaki personel iş ortamında ........gibidir/benzemektedir. Çünkü......" sorusuna verilen cevaplar analiz edilmiştir (Tablo 17).

Tablo 17: Katılımcıların Bankadaki Personelin iş Ortamındaki Durumlarına ilişskin Kullandıkları Metaforlar ve Analiz Bulguları

Bankadaki personel iş ortamın-

da.... gibidir/benzem

ktedir.
Metafor Anlam/Analiz

Arı, karınca, makine, motor,

Kene, avcı, yarış atı, aslan, panter

Aile, saç örgüsü, dost

Puzzle, takım, futbol takımı, saç örgüsü

Kafes, kâtip, öğretmen

Maske, akrep, telefon
Sürekli ve yoğun bir şekilde müşteri memnuniyetini sağlamak için çalışmakta oldukları Bankaya müşteri çekmek için sürekli yarış halinde ve hızlı hareket ettikleri

Bir personelin yaptığı işin diğer personelin yaptığı iş ile ilişkili olduğu

Takım ruhuyla hareket ettikleri

Verilen işi düzgün olarak iş sınırları içinde yapmaları gerektiği

Duruma göre değiştikleri, birbirlerinin canını acıtabilecekleri ve zarar verebilecekleri 
Banka çalışanları, sürekli ve yoğun olarak müşteri memnuniyetini sağlamak için çalıştıklarını, bankaya müşteri çekmek için hızlı olmaları gerektiğini belirtmektedirler. Bir personelin yaptığı işin diğer bir personelin yaptığı iş ile ilişki içerisinde olması durumu çalışanlar arasında farazi bir aile bağı kurulmasına neden olmaktadır. Banka çalışanlarının takım ruhuyla hareket ettikleri ifade edilmektedir. Çalışanların verilen işi iş sınırları içerisinde yapmak zorunda oldukları, personelin iş ortamında aslında yapmacık bir tavır sergiledikleri, olaya göre değiştikleri, birbirleriyle olan ilişkilerinde zaman zaman birbirlerine incitici ve üzücü davranabildikleri de vurgulanmaktadır. Bu durum takım ruhu konusunda belirtilenlerle örtüşmemektedir.

Çalışmada güç ilişkisinde kullanılan metaforları analiz etmek amacıyla "Bu bankadaki pozisyonum ........gibidir/benzemektedir. Çünkü......" sorusuna verilen cevaplar analiz edilmiştir (Tablo 18). Çalışanlar, bir yandan görev yaptıkları pozisyonun sürekli çalışmayı gerektirdiğini, iş odaklı düşündüklerini, bir yandan da oluşan sorunları çözmek için etkin bir konumda olduklarını ve müşteri odaklı çalıştıklarını ifade etmektedirler. Öyle ki kendilerini bütünün çok önemli bir parçası ve olmazsa olmaz asli unsuru olarak görmektedirler. Ne emredilirse uygulamak ve çalışmak zorunda olduklarını ve banka odaklı çalıştıklarını da ifade etmektedirler. Analiz sonuçlarında müşteri odaklılık vurgusu hakimdir.

Tablo 18: Katılımcıların Kendilerinin Bankadaki Pozisyonlarına ilişskin Kullandıkları Metaforlar ve Analiz Bulguları

\begin{tabular}{|c|c|c|}
\hline $\begin{array}{l}\text { Bu bankadaki pozisyonum } \\
\text {........gibidir/benzemektedir }\end{array}$ & Metafor & Anlam/Analiz \\
\hline & Arı, saat, işçi arı & $\begin{array}{l}\text { Bulundukları pozisyonun sürekli } \\
\text { çalışmayı gerektirdiği }\end{array}$ \\
\hline & $\begin{array}{l}\text { Anahtar, köprü, kapı kolu, } \\
\text { kılcal damar, sandalye ayağı, } \\
\text { polis, maymuncuk, doktor, } \\
\text { düğüm, giriş kapısı, ana yemek }\end{array}$ & $\begin{array}{l}\text { İş odaklı düşündükleri, oluşan } \\
\text { sorunları çözmek için etkin ko- } \\
\text { numda oldukları }\end{array}$ \\
\hline & $\begin{array}{l}\text { Vadeli mevduat, vezne, } \\
\text { kartal, kilit, Süpermen, } \\
\text { kumbara, mendil, pazarlamacı, } \\
\text { tezgahtar, papağan }\end{array}$ & $\begin{array}{l}\text { Müşteri odaklı düşünüp ona göre } \\
\text { çalıştıkları }\end{array}$ \\
\hline & Gonca gül, anne sütü, altın, gümüş, yıldız & $\begin{array}{l}\text { Kendilerini bütünün önemli birer } \\
\text { parçası olarak gördükleri }\end{array}$ \\
\hline & Acemi er, gurbetçi, yap boz, futbolcu, & Bu pozisyonun geçici olduğu \\
\hline & Robot, silah, mahkum & $\begin{array}{l}\text { Ne emredilirse uygulamak ve } \\
\text { çalışmak zorunda oldukları }\end{array}$ \\
\hline
\end{tabular}

Çalışmada güç ilişkisinde kullanılan metaforları analiz etmek amacıyla "Çalışma ortamım........gibidir/benzemektedir. Çünkü......" sorusuna verilen cevaplar analiz edilmiştir ( Tablo 19).

Banka çalışanlarının bir kısmı iş yerindeki ortamı bir aile ortamı gibi; sıcak, samimi, huzurlu ve çalışııması kolay bir yer olarak tanımlamaktadırlar. Çalışanların bir kısmı ise talimat ve kuralların olduğu sıkıcı, stresli bir ortam olarak görmektedir. Katılımcılar, çalışma ortamlarının kalabalık ve karmaşık olduğunu, renkli, kalabalık ve yoğun bu ortamda her çeşit insanın olduğunu da belirtmektedirler. 
Tablo 19: Katılımcıların Çalışma Ortamına ilişskin Kullandıkları Metaforlar ve Analiz Bulguları

Çalışma ortamım.........gibidir/

benzemektedir
Metafor

Ev, helva, şeker, süit oda, kuş tüyü minder, lüks otel, yatak, gündüz, şirinler

Hapishane, buzdolabı, hastane, sınav

zamanı, resmi tören, morg, heyet

kurulu, gece sessizliği

Leylek

Okul, orman, dağınık oda, sebze çorbası, asfalt, sezon indirimine girmiş mağaza, havuz, pazar yeri, metro, arı kovanı, dükkan, konser salonu, mut-

fak
Anlam/Analiz

İş yerindeki ortam sıcak, samimi, huzurlu ve çalışılması rahat bir yer olarak nitelendirilmekte

Talimat ve kuralların olduğu, sıkıcı, yaşamdan uzak, stresli bir ortam

Geçici bir süre burada bulundukları Kalabalık ve karmaşık, renkli ve yoğun bir çalışma ortamında her çeşit insan ile karşılaştıkları

Çalışmada örgütsel yapı için kullanılan metaforları analiz etmek amacıyla "Bu kuruluştaki çalışma hayatı ........gibidir/benzemektedir. Çünkü......" sorusuna verilen cevaplar analiz edilmiştir (Tablo 20). Çalışanlar, sürekli çalışmak zorunda olduklarını, her gün aynı işi yapsalar da zamanın çok çabuk geçtiğini ve zamanın nasıl geçtiğini fark edemediklerini vurgulamaktadırlar. Çalışma hayatının yorucu, kuralcı, bazen iyi bazen kötü olduğunu, hep çalışmak zorunda olduklarını, dört duvar arasında ağır sorumluluk taşıyan ve insanı yavaş yavaş tüketen bir iş hayatları olduğunu belirtilmektedirler. Çalışma hayatının olumlu tarafları olarak da zamanla güzelleştiği, değerlendiği ve eğlenceli yanlarının olduğu belirtilmektedir.

Tablo 20: Katılımcıların Bankadaki Çalışma Hayatına ilişskin Kullandıkları Metaforlar ve Analiz Bulguları

Bu kuruluştaki çalışma haya-

tı.........gibidir/benzemektedir

Metafor

Hızlı tren, su, ralli, uçak, ışık, saat, kitap, bilet gişesi, ATM, dizi film, robot, maden işçisi, karınca, trafik, at gözlügü takmak, motor, makine

Sürgün, askeri kışla, bazen zindan bazen çiçek bahçesi, uzun yol, askerlik, törpü, eşek, hapishane, bozuk para, uçan halı, hastalık

Aşk, dost, demlenmeye bırakılmış pilav, lunapark, kıvırcık saç, toprak

\section{Anlam/Analiz}

Sürekli çalışmak zorunda oldukları, her gün aynı işi yapsalar da zamanın çok hızlı geçtiği ve nasıl geçtiğini anlamadıkları

Çalışma hayatlarının yorucu, kuralcı, bazen iyi bazen kötü olduğu, hep çalışmak zorunda oldukları, dört duvar arasında çalıştıkları, tüm yükü kendilerinin çektiği, kendilerini törpüleyen bir tarafı olduğu, kendilerini harcanmış hissettikleri, insanı yavaş yavaş tüketeceği

Zamanla güzelleşeceği, değerleneceği, eğlenceli yanlarının da olduğu

\subsection{6.Örgüt Yapısı}

Çalışmada örgütsel yapı için kullanılan metaforları analiz etmek amacıyla "Hiyerarşik kademeler arasındaki ilişki........gibidir/benzemektedir. Çünkü......" sorusuna verilen cevaplar analiz edilmiştir. Analiz sonucunda metaforlar ve anlamlarına ilişkin bulgular Tablo 21' de yer almaktadır. Kuruluş içindeki hiyerarşik kademeler arasındaki ilişkide katı ve çiğnenmez kurallar 
olduğu ve bunların önemsendiği görülmektedir. Öyle ki kurallara riayet edilmediği takdirde ciddi cezalarla karşılaşılmaktadır. Hiyerarşik sistemin kuruluş içerisindeki birçok davranışa/aktiviteye yön verdiği ve kademeler arasında farklılıklar olduğu ifade edilmektedir. Bankada önceden belirlenmiş, yerleşmiş katı kuralların olduğu ve işlerin bu sisteme uygun olarak yürütüldüğü görülmektedir. Bu bulgular güç mesafesine dair kanıtlar da taşımaktadır.

Tablo 21: Katılımcıların Hiyerarşik Iilişkilere İlişkin Kullandıkları Metaforlar ve Analiz Bulguları Hiyerarşik kademeler arasındaki iliş-

ki........gibidir/benzemektedir.

Metafor

Anlam/Analiz

Askeriye, kanun, sınır çizgisi,
çerçeve, hukuk, ordu, rütbe,
periyot, katı kural, meclis, çivi,
diplomatik ilişki, buz, bıçak
Piramit, dağcılar, boy grafiği,
basamak, yelek düğmeleri,
matruşka

Çiğnenmesi zor, katı ve ağır kuralların olduğu, çalışanların bunları önemsedikleri, kurallara riayet edilmediği zaman ciddi cezaların olduğu Kademeler arasında farklııklar olduğu, bankada yerleşmiş katı kuralların bulunduğu ve işlerin bu sisteme uygun olarak yürütüldüğü

Çalışmada örgüt yapısı için kullanılan metaforları analiz etmek amacıyla "Bankanın çalışma ilkesi ........gibidir/benzemektedir. Çünkü......" sorusuna verilen cevaplar analiz edilmiştir (Tablo 22). Banka çalışanları, bankanın çalışma ilkesini uyulması gereken kurallar ile özdeşleştirmektedirler. Çalışanlar bir yandan ilkeler doğrultusunda sistemli bir şekilde çalışmanın başarı getireceğini düşünürken bir yandan da ilkelerin zorunluluk olduğunu düşünerek rahatsızlık duymaktadırlar. Sürekli ve düzenli olarak çalıştıklarını ve verilen işi bitirmek için çabaladıklarını belirtmektedirler. Bazı durumlarda tüccar gibi hareket ettiklerini çünkü para satarak kar elde ettiklerini ifade etmektedirler.

Tablo 22: Katılımcıların Bankanın Çalışma ilkesine Ilişkin Kullandıkları Metaforlar ve Analiz Bulguları

\begin{tabular}{|c|c|c|}
\hline $\begin{array}{l}\text { Bankanın çalışma ilkesi } \\
\text {........gibidir/benzemektedir }\end{array}$ & Metafor & Anlam/Analiz \\
\hline & $\begin{array}{l}\text { Anayasa, kanun, Atatürk ilkeleri, } \\
\text { Wilson ilkeleri, demokrasi, } \\
\text { müfredat, jeneratör, şeriat, ders } \\
\text { programı, devlet, üç öğün ye- } \\
\text { mek, kredi, sözleşme, ad-soyadı, } \\
\text { karınca, tükenmez kalem, }\end{array}$ & $\begin{array}{l}\text { Bankanın çalışma ilkesini kuruluşun } \\
\text { uyması gereken kurallar ile özdeşleş- } \\
\text { tirmekte, ilkeler doğrultusunda } \\
\text { sistematik bir çalışmanın başarı } \\
\text { getireceğini, ilkelere uymanın zorun- } \\
\text { luluk olduğu için rahatsızlık verdiğini } \\
\text { düşünmekteler }\end{array}$ \\
\hline & Ticarethane & $\begin{array}{l}\text { Tüccar gibi hareket ettikleri, çünkü } \\
\text { para satarak kar elde ettikleri }\end{array}$ \\
\hline & $\begin{array}{l}\text { Ticari taksi, beyin, zaman, ritim, } \\
\text { saat, başarılı patron, fabrika, arı } \\
\text { kovanı, ekmek fırını }\end{array}$ & $\begin{array}{l}\text { Sürekli ve düzenli olarak çalıştıkları, } \\
\text { verilen işi bitirmek zorunda oldukları }\end{array}$ \\
\hline
\end{tabular}

Çalışmada örgütsel yapı için kullanılan metaforları analiz etmek amacıyla "Bankadaki kurallar ........gibidir/benzemektedir. Çünkü......" sorusuna verilen cevaplar analiz edilmiştir (Tablo 23). Bankadaki kuralların, esnek olmadığı, uyulmasının zorunlu olduğu, uyulmazsa cezalar ile karşılaşılacağı, iş ortamında olması gereken bir olgu oldukları belirtilmektedir. Katılımcılar bu kuralların yol gösterici, düzen sağlayıcı ve birbirine bağlı olduklarını ifade etmektedirler. Bankadaki kurallar kesin ve nettir. 
Tablo 23: Katılımcıların Bankadaki Kurallara ilişkin Kullandıkları Metaforlar ve Analiz Bulguları

\begin{tabular}{|c|c|c|}
\hline $\begin{array}{l}\text { Bankadaki kurallar } \\
\text {.............gibidir/benzemektedir }\end{array}$ & Metafor & Anlam/Analiz \\
\hline & $\begin{array}{l}\text { Duvar, demir, granit, anayasa, } \\
\text { sınır çizgisi, kaya, kale duvarı, } \\
\text { buz, çelik, genel kurmay, marga- } \\
\text { rin, nizamiye, Hammurabi Kanun- } \\
\text { ları, Hipokrat yemini, okul kuralı }\end{array}$ & $\begin{array}{l}\text { Kuralların esnek olmadığı, katı olduğu } \\
\text { ve uyulmasının zorunlu olduğu, } \\
\text { eskiden yerleşmiş ve halen uygulan- } \\
\text { makta oldukları }\end{array}$ \\
\hline & $\begin{array}{l}\text { Keskin bıçak, soba, kılıç, trafik } \\
\text { kuralı }\end{array}$ & Uyulmaz ise cezalarla karşılaşılacağı \\
\hline & $\begin{array}{l}\text { Kek malzeme listesi, kitabın } \\
\text { içindekiler sayfası }\end{array}$ & $\begin{array}{l}\text { İş ortamında olması gereken, olmazsa } \\
\text { olmaz bir olgu oldukları }\end{array}$ \\
\hline & Dantel & $\begin{array}{l}\text { Kuralların hepsinin birbirine bağlı ve } \\
\text { net olduğu }\end{array}$ \\
\hline
\end{tabular}

\subsection{7. İletişim}

Çalışmada örgüt kültürü açısından iletişim için kullanılan metaforları analiz etmek amacıyla "Bankada bölümler arasındaki ilişki........gibidir/benzemektedir. Çünkü......" sorusuna verilen cevaplar analiz edilmiştir. Analiz sonucunda metaforlar ve anlamlarına ilişkin bulgular Tablo 24 'de yer almaktadır. Katılımcılar, bankadaki bölümlerin yaptıkları işler açısından birbirleriyle sıkı bir ilişki içerisinde olduklarını belirtmektedirler. Bir bölümün başarısızlığının diğer bölümlerdeki iş akışını etkileyeceği düşünülmektedir. Buna karşın bölümler arası ilişkiler kurallarla belirlenmiş ve rekabetçidir. İlişkiler karmaşık olmakla birlikte sorun olması halinde çözümleyici bir iletişim ortamı bulunmaktadır.

Tablo 24: Katılımcıların Bankadaki Bölümler Arasındaki Ilişkiye Dair Kullandıkları Metaforlar ve Analiz Bulguları

\begin{tabular}{|c|c|c|}
\hline $\begin{array}{l}\text { Bankada bölümler arasındaki iliş- } \\
\text { ki.........gibidir/benzemektedir }\end{array}$ & Metafor & Anlam/Analiz \\
\hline & $\begin{array}{l}\text { Zincir, tren vagonu, elmanın iki } \\
\text { yarısı, hücre, komşu, aynı ordunun } \\
\text { farklı bölükleri, denizci düğümü, } \\
\text { çapraz bağ, başbakan ve yardımcı- } \\
\text { sı, hastane poliklinikleri, çay ve } \\
\text { şeker }\end{array}$ & $\begin{array}{l}\text { Bölümler arasında yapılan işle orantılı } \\
\text { olarak, sıkı bir ilişki olduğu, birisindeki } \\
\text { başarısızlığın diğerini etkilediği, } \\
\text { bölümler farklı olsa da yapılan işin ve } \\
\text { hedefin aynı olduğu }\end{array}$ \\
\hline & $\begin{array}{l}\text { Bıçak, ince ip, anahtar, zengin } \\
\text { fakir, ayrı sınıftaki çocuklar, yarış } \\
\text { atı, zeytinyağı, çerçeve }\end{array}$ & $\begin{array}{l}\text { Bölümler arasındaki ilişkiler kesin } \\
\text { kurallarla ayrılmakta, her bölüm } \\
\text { kendi işiyle ilgilenmekte, rekabet } \\
\text { içindeler, haklı olan galip gelme } \\
\text { çabasında }\end{array}$ \\
\hline & Klima, nane limon & $\begin{array}{l}\text { İlişkilerin durumlara göre farklılaştığı } \\
\text { (bazen yakın, bazen uzak olduğu) }\end{array}$ \\
\hline & Çorba, tarak & $\begin{array}{l}\text { İlişkilerin karmaşık olduğu fakat } \\
\text { çözülebildiği }\end{array}$ \\
\hline
\end{tabular}

Çalışmada iletişim için kullanılan metaforları analiz etmek amacıyla "Bankadaki haberler........gibidir/benzemektedir. Çünkü......" sorusuna verilen cevaplar analiz edilmiştir (Tablo 25). Banka çalışanları, bankadaki haberlerin çok hızlı yayıldığını ifade etmişlerdir. Duyulduğunda çalışanlar üzerinde şaşırtıcı etkisi olduğu, bazı haberlerin gerçek dışı olsa bile gündeme 
geldiği belirtilmektedir. Haberlerin günlük olarak sürekli yenilendiği, geçici olduğu ve tekrarlandığı ifade edilmektedir. Bankadaki önemli haberler çarpıcı ve dikkat çekici şekilde sunulmakta, sürekli gündemde tutulmakta, merak uyandırmakta ve etki yaratmaktadır.

Tablo 25: Katılımcıların Bankadaki Haberlere ilişkin Kullandıkları Metaforlar ve Analiz Bulguları

\begin{tabular}{|c|c|c|}
\hline $\begin{array}{l}\text { Bankadaki haberler.........gibidir } \\
\text { /benzemektedir }\end{array}$ & Metafor & Anlam/Analiz \\
\hline & $\begin{array}{l}\text { Jet, ışık hızı, internet, çita, yıldırım, } \\
\text { yeni çıkan ekmek, yeni sıcak simit, } \\
\text { facebook, roket, füze }\end{array}$ & Haberlerin çok hızlı yayılıp, duyulduğu \\
\hline & $\begin{array}{l}\text { Sürpriz yumurta, bomba, flaş } \\
\text { haber, fırtına, parfüm, kaynamış su, } \\
\text { yangın, ebeleme oyunu }\end{array}$ & $\begin{array}{l}\text { Duyulduğunda çalışanlar üzerinde } \\
\text { şaşırtıcı etkisi olduğu }\end{array}$ \\
\hline & Pembe dizi, balon & $\begin{array}{l}\text { Bazı haberlerin gerçek dışı da olsa } \\
\text { gündeme geldiği }\end{array}$ \\
\hline & $\begin{array}{l}\text { Fıkra, gazete, saç boyası, son } \\
\text { dakika, akarsu, TV reklamı, üçüncü } \\
\text { sayfa haberleri }\end{array}$ & $\begin{array}{l}\text { Haberlerin günlük olarak sürekli } \\
\text { yenilendiği, geçici olduğu ve tekrar- } \\
\text { landığı }\end{array}$ \\
\hline & Makyaj, magazin & $\begin{array}{l}\text { Önemli haberlerin değiştirildiği ve } \\
\text { merak uyandırdığı, gündemde olduğu }\end{array}$ \\
\hline
\end{tabular}

Çalışmada iletişim için kullanılan metaforları analiz etmek amacıyla "Bankadaki törenler........gibidir/benzemektedir. Çünkü......" sorusuna verilen cevaplar analiz edilmiştir (Tablo 26). Katılımcılar, bankada organize edilen törenlerde arkadaşlarıyla bir araya geldiklerini, neşeli, samimi bir ortam oluştuğundan dolayı kendilerini mutlu hissettiklerini ancak zaman zaman böyle ortamların zevksiz, sıkıcı, resmi olduğunu, çalışanlarda gerginlik yarattığını, çok sıkıcı olsa da kutlanmasının mecburi olduğunu, hiç olmasa daha iyi olacağını, sürekli işten konuşulduğunu ifade etmektedirler. Genellikle vedalarda bir araya gelindiği ve bu törenlerden geriye gelecekte hatırlanacak anılar kaldığı da belirtilmektedir. 
Tablo 26: Katılımcıların Bankadaki Törenlere ilişskin Kullandıkları Metaforlar ve Analiz Bulguları

\begin{tabular}{|c|c|c|}
\hline $\begin{array}{l}\text { Bankadaki törenler.........gibidir/ } \\
\text { Benzemektedir. }\end{array}$ & Metafor & Anlam/Analiz \\
\hline & $\begin{array}{l}\text { Düğün, panayır, bayram, } \\
\text { Festival, altın günü, ilkbahar, } \\
\text { düğün yemeği, birinci sınıf çocuk- } \\
\text { ların karne heyecanı, bayram } \\
\text { şekeri, yılsonu etkinliği, hafta sonu } \\
\text { tatili, konser, disko, evlilik yıldö- } \\
\text { nümü, çöldeki orman }\end{array}$ & $\begin{array}{l}\text { Bu törenlerde arkadaşlarıyla bir araya } \\
\text { geldikleri, neşeli, samimi bir ortam } \\
\text { oluştuğu için kendilerini mutlu hisset- } \\
\text { tikleri }\end{array}$ \\
\hline & Şampuan & $\begin{array}{l}\text { Bu tür organizasyonların abartılarak } \\
\text { yapıldığı için rahatsızlık uyandırdığı }\end{array}$ \\
\hline & $\begin{array}{l}\text { Tuzsuz yemek, diken, soru çözmek, } \\
\text { cenaze, adada kalmış insan, kural, } \\
\text { toplantı }\end{array}$ & $\begin{array}{l}\text { Bu tür ortamların zevksiz, resmi ve } \\
\text { çok sıkıcı olduğu, çalışanlarda gergin- } \\
\text { lik yarattığı ama kutlanması gerektiği }\end{array}$ \\
\hline & Gözyaşı & $\begin{array}{l}\text { Genellikle vedalarda bir araya gelindi- } \\
\text { ği } \\
\text { ileride hatırlanacak anıların olustuğu }\end{array}$ \\
\hline & & meride natırlanacak aniların oiuştugu \\
\hline
\end{tabular}

Çalışmada iletişim için kullanılan metaforları analiz etmek amacıyla "Bankada personel arasındaki ilişki ........gibidir/benzemektedir. Çünkü......" sorusuna verilen cevaplar analiz edilmiştir (Tablo 27). Banka çalışanları, birbirlerini iyi tanıdıklarını, herkesin birbirine yardımcı olduğunu, takım ruhuyla hareket ettiklerini, resmiyet ve kurallar olduğunu, ilişkilerde kurallara uymak gerektiğini, karşııkı bağımlıık nedeniyle de iyi geçindiklerini belirtmektedirler. Bazı çalışanlar ise ilişkilerde sahtelik olduğunu ve yarışmacı bir iklim içinde bulunduklarını ifade etmektedirler.

Tablo 27: Katılımcıların Bankada Personel Arasındaki Ilişkiye Dair Kullandıkları Metaforlar ve Analiz Bulguları

\begin{tabular}{|c|c|c|}
\hline $\begin{array}{l}\text { Bankada personel arasındaki } \\
\text { ilişki.........gibidir/benzemektedir }\end{array}$ & Metafor & Anlam/Analiz \\
\hline & Aile, kardeş, arkadaş & $\begin{array}{l}\text { Çalışanların birbirini iyi tanıdığı ve } \\
\text { birbirlerine yardımcı olduğu }\end{array}$ \\
\hline & $\begin{array}{l}\text { Futbol takımı, yol arkadaşı, baba- } \\
\text { oğul, kaymaklı kadayıf, örgü } \\
\text { örmek, tahin pekmez, bağ, zincir, } \\
\text { sevgililer, halat }\end{array}$ & $\begin{array}{l}\text { Ekip arkadaşlarının birbiriyle uyumlu } \\
\text { ve birbirine bağlı olarak çalıştığı }\end{array}$ \\
\hline & $\begin{array}{l}\text { Palyaço, sahte para, siyasetçi, } \\
\text { klima, yapmacık, }\end{array}$ & $\begin{array}{l}\text { İlişkileri kötü olsa da iyi görünmek } \\
\text { zorunda oldukları, bazen iyi bazen } \\
\text { kötü oldukları, birbirlerine işleri } \\
\text { düştükleri için iyi geçinmek durumun- } \\
\text { da oldukları }\end{array}$ \\
\hline & Güneş, lav & $\begin{array}{l}\text { Illişkilerinin sıcak ama zarar verici } \\
\text { olabildiği }\end{array}$ \\
\hline & $\begin{array}{l}\text { Okeye dördüncü, takım oyunu, } \\
\text { karınca, domino taşları, zincir } \\
\text { halkası }\end{array}$ & Çalışanların birbirini tamamladıkları \\
\hline & Meclis, koşucu, hiyerarşi & $\begin{array}{l}\text { Kural ve resmiyet olduğu, sürekli yarış } \\
\text { içinde oldukları }\end{array}$ \\
\hline
\end{tabular}


Çalışmada iletişim için kullanılan metaforları analiz etmek amacıyla "Personel arasındaki bağlar...........gibidir/benzemektedir. Çünkü......" sorusuna verilen cevaplar analiz edilmiştir (Tablo 28).

Tablo 28: Katılımcıların Bankada Personel Arasındaki Bağlara ilişkin Kullandıkları Metaforlar ve Analiz Bulguları

\begin{tabular}{|c|c|c|}
\hline $\begin{array}{l}\text { Personel arasındaki } \\
\text { bağlar............gibidir/benzemektedir }\end{array}$ & Metafor & Anlam/Analiz \\
\hline & $\begin{array}{l}\text { Halat, çelik, demir, zincir, kilit, } \\
\text { anne- çocuk, ipe atılmış düğüm, } \\
\text { atar damar, iyonik bağ, lif, aile, } \\
\text { vagon }\end{array}$ & $\begin{array}{l}\text { Çalışma arkadaşlarıyla oldukça güçlü } \\
\text { bağları olduğu, ekip çalışmasının getirdi- } \\
\text { ği iletişim ve yardımlaşmanın bu bağı } \\
\text { güçlendirdiği }\end{array}$ \\
\hline & $\begin{array}{l}\text { Pamuk ipliği, göbek bağı, örüm- } \\
\text { cek ağı, yay, kıl, maske, göz } \\
\text { kırpması, kuş yuvası }\end{array}$ & $\begin{array}{l}\text { Bağları kuvvetli olsa da en ufak bir } \\
\text { problemde bu bağların kopabileceği, } \\
\text { dostluklarının bozulabileceği }\end{array}$ \\
\hline & Tarak & $\begin{array}{l}\text { Çalışanlar arasındaki ilişkinin seçici } \\
\text { ilişkiler olduğu }\end{array}$ \\
\hline & Naylon ip & $\begin{array}{l}\text { Olumsuz şartlarda bile bağların kopma- } \\
\text { yacağı }\end{array}$ \\
\hline & $\begin{array}{l}\text { Domino taşı, üzüm bağı, } \\
\text { İnternet ağı }\end{array}$ & $\begin{array}{l}\text { İki çalışan arasında yaşanan olumsuzlu- } \\
\text { ğun tüm çalışanları etkilediği }\end{array}$ \\
\hline
\end{tabular}

Banka personeli çalışma arkadaşlarıyla olan bağlarını oldukça güçlü olarak nitelendirmektedirler. Ekip çalışmasının getirdiği iletişim ve yardımlaşma personelin kendi arasındaki bağı ve paylaşımı oldukça güçlendirmiştir. Çalışanlar arasındaki bağların çok olumsuz şartlarda bile kopmayacağı, iki çalışan arasındaki sorunların diğerlerini de etkileyeceği vurgulanmaktadır. Bazı çalışanlar ise kendilerini diğer arkadaşlarına yakın görmekle birlikte oluşabilecek en ufak bir problemde dostluk ortamının bozulabileceğini, ilişkilerin kırılgan olduğunu belirtmektedirler. Bireyler arasındaki sorunların tüm çalışanları etkilediği de vurgulanmaktadır.

Çalışmada iletişim için kullanılan metaforları analiz etmek amacıyla "Çalışanlar arasındaki dil..........gibidir/benzemektedir. Çünkü......" sorusuna verilen cevaplar analiz edilmiştir (Tablo29).

Tablo 29: Katılımaların Bankadaki Personel Arasında Kullanılan Dile Ilişkin Kullandıkları Metaforlar ve Analiz Bulguları

Çalışanlar arasındaki

dil...........gibidir/benzemektedir
Metafor

Yabancı dil, Çince, Fransızca,

Rusça, İngilizce, Arapça, Korece,

Azerice, Hint dili, şifre, sözlük, prospektüs

Şeker, krema, bale, su, şelale, ahenk, müzik

Zeki Müren, İstanbul Türkçesi,

Türk Dil Kurumu, diksiyon, gra-

mer,

Siyah, vızıltı, sivri vızıltısı
Anlam/Analiz

Kendi aralarında konuşulan dilin sektöre has olduğu ve herkesin anlamayacağ

Kulağa hoş gelen ve nazik bir dil kullandıkları

Kelimelerin özenle seçildiği, düzgün, anlaşılır, kibar bir dil kullanıldığı

Dilin resmi ve anlaşılmasının güç olduğu 
Çalışanlar, kendi aralarında konuştukları dilin sektöre has olduğunu ve herkesin anlayamayacağını düşünmektedirler. Her ne kadar kendi aralarındaki konuşma dili yabancı kelimelerin ya da sektörel terimlerin çokluğu nedeniyle başkaları tarafından anlaşılmasa da personel birbirini çok iyi anlamaktadır. Kendi aralarındaki dili olumlu ifadelerle nitelendirmişlerdir. Kelimelerin özenle seçildiği, düzgün, anlaşılabilir, kibar bir dil kullanıldığı vurgulanmaktadır. Konuşulan dil resmi ve anlaşılması güç olsa da, bankadaki örgüt kültüründe çalışanların kendilerine has ortak bir dili olduğu ve nezaketin hâkim olduğu anlaşılmaktadır.

Çalışmada iletişim için kullanılan metaforları analiz etmek amacıyla "İşe yeni başlayanlara bankayla ilgili anlatılan hikayeler............gibidir/benzemektedir. Çünkü......" sorusuna verilen cevaplar analiz edilmiştir. Analiz sonucunda metaforlar ve anlamlarına ilişkin bulgular Tablo 30 'da yer almaktadır.

Tablo 30: Katılımcıların Bankada Iş̧e Yeni Başlayanlara Banka ile ilgili Anlatılan hikâyelere ilişkin Kullandıkları Metaforlar ve Analiz Bulguları

İşe yeni başlayanlara anlatılan hikayeler.....gibidir/benzemektedir

Metafor
Dede Korkut Hikâyeleri, fırtına,
anne öğüdü, rivayet, askerlik
anısı, pamuk prenses masalı,
şarkı, rafadan yumurta
Korku filmi, kâbus, Drakula,
canavar, testere filmi, korku
tüneli, dev, belgesel, zombi
hikâye, kuş, telefon rehberi,
sakız, balon, film, stand up
Hayal, masal, rüya, efsane

Metafor

Dede Korkut Hikâyeleri, fırtına

anne öğüdü, rivayet, askerlik

şarkı, rafadan yumurta

Korku filmi, kâbus, Drakula

canavar, testere filmi, korku

hikâye, kus, telefon rehberi,

Hayal, masal, rüya, efsane
Anlam/Analiz

Geçmişte yaşanan olaylar hikâyeleştirilerek anlatıldığı ve çalışanların bunlardan kendilerine ders çıkardı̆̆ı

Daha önce yaşanmış ve gelecekle alakalı olmayan, genelde olumsuz ve kötü hikâyelerin abartılarak ve eğlenceli şekilde anlatıldı̆̆

Yaşanmamış olaylar anlatılırken oldukça inandırıcı olmaya çalışıldığı

Bankada yeni işe başlayanlara, daha önce yaşanmış veya gerçekle alakalı olmayan, genelde olumsuz ve kötü hikâyeler, abartılarak ve eğlenceli bir şekilde anlatılmaktadır. Bu hikâyelerin asıl amacı örgütün kültürünü yeni işe başlayanlara aktarmak, gözdağı vererek hata yapmasını engellemek ve biraz da eğlenmektir.

Çalışmada iletişim için kullanılan metaforları analiz etmek amacıyla "Bankanın dış çevreyle ilişkisi...........gibidir/benzemektedir. Çünkü......" sorusuna verilen cevaplar analiz edilmiştir. Analiz sonucunda metaforlar ve anlamlarına ilişkin bulgular Tablo 31'de yer almaktadır.

Bankanın müşterilerine samimi, sıcak, anında dertlerine çözüm üreten, aydınlatan, onları iyi ağırlayan, onları ziyaret eden bir yapıda olduğu belirtilmektedir. Kullanılan metaforlara göre banka parlak, güzel ve tatlı dil ile yaklaşan, yapmacık, sürekli yüzünün gülmesi gereken, ortama göre davranan, süslü ve gösterişli, yeri geldiğinde katı ve sağlam olmak zorundadır. Bunlar özellikle imaja yönelik temenniler olup bankanın gerek potansiyel müşterileri gerekse kurumsal paydaşları nezdinde olumlu bir imaja sahip olması gerektiğini vurgulamaktadır. 
Tablo 31: Katılımcıların Bankanın Dış Çevre Ile Iliş̧kisine Dair Kullandıkları Metaforlar ve Analiz Bulguları

\begin{tabular}{|c|c|c|}
\hline $\begin{array}{l}\text { Bankanın dış çevreyle } \\
\text { ilişkisi............gibidir/benzemektedir. }\end{array}$ & Metafor & Anlam/Analiz \\
\hline & $\begin{array}{l}\text { Aile, sevgili, soba, Hızır, akut, } \\
\text { iyi esnaf, komşuluk ilişkisi, } \\
\text { sokak lambası, ateş, misafir, } \\
\text { yıldız, akraba, uçan halı }\end{array}$ & $\begin{array}{l}\text { Müşterilerine samimi ve sıcak dav- } \\
\text { randıkları, anında dertlerine çözüm } \\
\text { ürettikleri, aydınlattıkları, onları iyi } \\
\text { ağırladıkları, zaman zaman da ziyaret } \\
\text { ettikleri }\end{array}$ \\
\hline & $\begin{array}{l}\text { Ay, güneş, çiçek, bal, su, gül, } \\
\text { dantel, şekerpare, assolist, } \\
\text { albay, palyaço, gülen surat, } \\
\text { giysi, dükkân vitrini, bukale- } \\
\text { mun }\end{array}$ & $\begin{array}{l}\text { Dışarıya karşı parlak, güzel, tatlı dil } \\
\text { ile yaklaşan, yerine göre yapmacık } \\
\text { davranan, sürekli yüzü gülmesi } \\
\text { gereken, süslü, gösterişli, yeri geldi- } \\
\text { ğinde de katı ve sağlam durmasını } \\
\text { bilen }\end{array}$ \\
\hline & $\begin{array}{l}\text { Sünger, kuruyemiş, pazaryeri, } \\
\text { gökkuşağı, üvey kardeş, mıkna- } \\
\text { tıs, kene, doğa-insan }\end{array}$ & $\begin{array}{l}\text { Bankaya müşteri çekebilmek için } \\
\text { ilişkilerinin iyi olması gerektiği, çok } \\
\text { çeşitli müşteri topluluğuna hitap } \\
\text { ettikleri }\end{array}$ \\
\hline & Kahve & $\begin{array}{l}\text { İlişkilerinin sağlam ve unutulmaz } \\
\text { olduğu }\end{array}$ \\
\hline
\end{tabular}

Çalışmada iletişim için kullanılan metaforları analiz etmek amacıyla "Bu bankadaki teknoloji...........gibidir/benzemektedir. Çünkü......" sorusuna verilen cevaplar analiz edilmiştir. Analiz sonucunda metaforlar ve anlamlarına ilişkin bulgular Tablo 32' de yer almaktadır.

Tablo 32: Katılımcıların Bankadaki Teknolojiye Illişkin Kullandıkları Metaforlar ve Analiz Bulguları

\begin{tabular}{lll}
\hline $\begin{array}{l}\text { Bu bankadaki teknoloji } \\
\text {..........gibidir/benzemektedir }\end{array}$ & Metafor & Anlam/Analiz \\
\hline \hline & $\begin{array}{l}\text { Hızlı tren, ralli, internet, jet, Sü- } \\
\text { permen, kızlar koğuşu, android } \\
\text { telefon, Iphone, motor, fiber } \\
\text { internet, çita, modern teknoloji, } \\
\text { son model araba, ı̧ık hızı }\end{array}$ & $\begin{array}{l}\text { Kullanılan teknolojinin son derece hızlı } \\
\text { olduğu }\end{array}$ \\
& $\begin{array}{l}\text { At arabası, kağnı, aksak insan, } \\
\text { nostalji, patlak teker, kaplumbağa, } \\
\text { taş devri, solucan, bozuk saat, }\end{array}$ & $\begin{array}{l}\text { Kullanılan teknolojinin yavaş çalıştığı ve } \\
\text { eski olduğu }\end{array}$ \\
& $\begin{array}{l}\text { Orta kahve } \\
\text { Çocuk, tohum, zaman, Japonlar, } \\
\text { telefon, para, Microsoft }\end{array}$ & $\begin{array}{l}\text { Ne hızlı ne de yavaş olduğu } \\
\text { Teknolojinin sürekli geliştiği ve sürekli } \\
\text { kendini yenilediği }\end{array}$ \\
\hline
\end{tabular}

Bankadaki teknolojiye ilişkin metaforlarda bir tutarlılık olmadığı gözlenmektedir. Çalışanların çoğunluğu banka altyapısındaki teknolojinin oldukça hızlı olduğunu düşünürken, yavaş olduğunu düşünenler de azımsanmayacak orandadır. Buna rağmen bankanın teknolojisini geliştirdiği ve yenilediği de belirtilmektedir. Bu bulgulardan, banka çalışanlarının teknoloji hakkındaki görüşlerinin kişisel beklentilere göre farklılık göstermekte olduğu çıkarımı yapılabilir. Bu sonuçlar bankanın altyapısında belirli dönemlerde sıkıntılar yaşandığını, ancak bankanın teknolojisinin sürekli yenilendiğini göstermektedir.

Çalışmada iletişim için kullanılan metaforları analiz etmek amacıyla "Bankadaki kılık kıyafet düzeni...........gibidir/benzemektedir. Çünkü......" sorusuna verilen cevaplar analiz edilmiştir. 
Analiz sonucunda metaforlar ve anlamlarına ilişkin bulgular Tablo 33'te yer almaktadır. Bankadaki kılık/kıyafet uygulamasında katı kuralların mevcut olduğu vurgulanmaktadır. Banka personelinin kılık kıyafetlerinin aslında bankayı yansıttığı bunun için güzel, hoş, bakımlı giyinerek özenli olmaları gerektiği belirtilmektedir. Çalışanların aynı tarz giyinmesi gerektiği ve giyim konusunda yeterince özgür olmadıkları ifade edilmektedir.

Tablo 33: Katılımcıların Bankadaki Kılık/kıyafet düzenine Ilişkin Kullandıkları Metaforlar ve Analiz Bulguları

Bankadaki kılık kıyafet düzeni...........gibidir/ Benzemektedir.
Metafor

Kitap, jilet, kalem, cetvel, çizgi, askı, uçak host ve hostes, mağaza vitrini, tespih, ip, kılavuz, askeri düzen, kalem, zarf, raf, kütüphane

Forma, üniforma, takım forması, okul, öğrenci önlükleri

Kanun, fes kanunu, kural, ilkokul

Bülent Ersoy, manken, salon takımı, makam otosu, iş toplantıları, modacı
Anlam/Analiz

\author{
Bankadaki kılık/kıyafet düzeninde \\ kuralların hâkim olduğu ve bu kuralla- \\ rın yerleşmiş olduğu
}

Çalışanların aynı tarz giyinmesi gerektiği

Giyim konusunda yeterince özgür olmadıkları

Kıyafetin bankayı yansıttığı, bunun için güzel, hoş, bakımlı ve özenli giyindikleri

Çalışma sonunda araştırmanın gerçekleştirildiği kamu bankasında çalışanların kullandıkları metaforların analizi sonucunda örgüt kültürüne ilişkin paradigmalar ortaya konulmuştur (Tablo 34).

Tablo 34: Araştırmanın Gerçekleştirildiği Kamu Bankasında Çalışanların Kullandıkları MetaforIarın Analizi Sonucunda Örgüt Kültürüne Dair Elde Edilen Paradigmalar

\begin{tabular}{|c|c|}
\hline \multirow[t]{4}{*}{ Örgüt kimliği } & $\begin{array}{l}\text { Banka güven duyulan, korunaklı hissedilen büyük ve büyümeye devam eden aile gibi } \\
\text { hissedilen bir kuruluştur }\end{array}$ \\
\hline & $\begin{array}{l}\text { Bankanın köklü geçmişine saygı duyulmaktadır. Köklü geçmişinden gelen büyüklü- } \\
\text { gün ve etkinin devam edeceğine inanılmaktadır. }\end{array}$ \\
\hline & Gelecekte büyüme ve gelişme beklentisi yüksektir \\
\hline & $\begin{array}{l}\text { Çalışanlar kendilerini bankaya ait, yakın ve banka için değerli olduklarını hissetmek- } \\
\text { tedirler }\end{array}$ \\
\hline \multirow[t]{2}{*}{ Performans Ödül ílişkisi } & Terfi sistemi disiplin ve çalışma gerektirmekte, zor ancak adildir \\
\hline & $\begin{array}{l}\text { Ödüller çalışanları motive etmesine karşın yeterli değildir. Ödüllerin verilmesi konu- } \\
\text { sunda uzlaşılmış standartlar yoktur. }\end{array}$ \\
\hline \multirow[t]{2}{*}{ Risk Üstlenmeyi Teşvik } & $\begin{array}{l}\text { Yeni fikirleri olanlara örgüt ve yönetim tarafından değer verilmektedir. Bu kişiler } \\
\text { azınlıkta ve kıymetlidir ancak diğer çalışanlarca desteklenmemektedir. }\end{array}$ \\
\hline & $\begin{array}{l}\text { Hataya tolerans yoktur, hata yapanlar suçlanmakta ve sistem dışı bırakılmakta olup } \\
\text { mükemmeliyetçilik yaygındır. }\end{array}$ \\
\hline \multirow[t]{5}{*}{ Güç iliş̧kileri } & $\begin{array}{l}\text { Lider sorumluluk sahibi, çalışanları yönlendiren, yol gösteren, vazgeçilmez, hükme- } \\
\text { dici ve kibirli olarak görülmektedir. }\end{array}$ \\
\hline & $\begin{array}{l}\text { Yöneticilerin iş ortamındaki davranışları koruyucu, yönlendirici, bilgi sahibi, aile reisi } \\
\text { gibi, cezalandırıcı, katı ve hükmedici olarak görülmektedir. }\end{array}$ \\
\hline & $\begin{array}{l}\text { Çalışanlar kendilerini bankanın asli unsuru olarak görmektedir. Vitrinde yer aldıkları, } \\
\text { dış görüntünün önemli olduğu, kontrol ve gözetim altında oldukları, bireyin metalaş- } \\
\text { tığı ve mekanik bir ilişki biçiminin hâkim olduğu düşüncesi yaygındır. }\end{array}$ \\
\hline & $\begin{array}{l}\text { Yöneticiler ile iş dışı ilişkilerin olduğu ve banka dışında personelin sıkıntılarını ve } \\
\text { sırlarını paylaştıkları görülmektedir. }\end{array}$ \\
\hline & Banka personeli yöneticiler için üreten, çalışan, olmazsa olmaz unsurlar olmakla \\
\hline
\end{tabular}




\begin{tabular}{|c|c|}
\hline & birlikte çok çalışmak ek bir getirisi olmadığı için olumsuz algılanmaktadır. \\
\hline & $\begin{array}{l}\text { Yöneticilerin makam odası gösterişli, gücü simgeleyen ve bankanın dışarısı ile ilişki- } \\
\text { sinin başladığı, önemli kararların alındığı, yöneticilerin güçlerini buradan aldığı } \\
\text { mekânlar olarak görülmektedir. }\end{array}$ \\
\hline \multirow[t]{4}{*}{ Personel ve İş ilişkileri } & $\begin{array}{l}\text { İşyerinde müşteri memnuniyeti için birlikte ve çok çalışma, yarışma, zaman zaman } \\
\text { birbirlerini üzecek şekilde davranma söz konusudur. }\end{array}$ \\
\hline & $\begin{array}{l}\text { Müşteri odaklılık, çok çalışmak, sorun çözmek, bütünün bir parçası olmak düşüncesi } \\
\text { hâkimdir. }\end{array}$ \\
\hline & $\begin{array}{l}\text { Bankanın çalışma ortamı bazı çalışanlar için sıcak, samimi aile ortamı, bazı çalışanlar } \\
\text { için de talimatların olduğu, yaşamdan uzak, stresli bir ortamdır. }\end{array}$ \\
\hline & $\begin{array}{l}\text { Sürekli çalışma gerektiren, yorucu, kuralcı, insanı yavaş yavaş tüketen, zaman zaman } \\
\text { eğlenceli de olabilen bir çalışma hayatı algısı hâkimdir. }\end{array}$ \\
\hline \multirow[t]{3}{*}{ Örgüt Yapısı } & $\begin{array}{l}\text { Hiyerarşik ilişkilerde katı ve çiğnenmez kurallar bulunmakta kurallara riayet edilme- } \\
\text { mesi halinde ciddi cezalar alınmaktadır. }\end{array}$ \\
\hline & $\begin{array}{l}\text { Çalışma ilkesi sürekli çalışma, para ve kurallardan oluşmaktadır. Kurallara uyulması } \\
\text { başarı getirmekle birlikte zorunluluk olduğu için rahatsızlık verici görülmektedir. }\end{array}$ \\
\hline & $\begin{array}{l}\text { Kesin, olması gerektiğine inanılan, birbirine bağlı ve düzen sağlayııı olarak görülen, } \\
\text { uyulmazsa cezalarla karşılaşılan katı kurallar hâkimdir. }\end{array}$ \\
\hline \multirow[t]{10}{*}{ İletişim } & $\begin{array}{l}\text { Banka için ortak hedef etrafında, sıkı ve birbirine bağlı ilişkiler söz konusudur. Ancak } \\
\text { bölümler arası ilişkiler, kurallarla belirlenmekte, rekabetçi, karmaşık ama sorun } \\
\text { çıktığında çözülebilen ilişkilerdir. }\end{array}$ \\
\hline & $\begin{array}{l}\text { Bankadaki haberler merak uyandırmakta, sürekli değişmekte, hızlı yayılmakta olup } \\
\text { bazen gerçek dışıdır. }\end{array}$ \\
\hline & $\begin{array}{l}\text { Törenler, çalışanların bir araya gelmesinden dolayı mutluluk verici ancak resmi, } \\
\text { sıkıcı, gerginlik verici olabilen durumlar olarak algılanmaktadır. }\end{array}$ \\
\hline & $\begin{array}{l}\text { Çalışanlar arasındaki ilişkiler sıcak, karşılıklı bağımlı olması nedeniyle sürdürülmesi } \\
\text { gereken, zaman zaman rekabetçi, zarar verici ve sahtedir. }\end{array}$ \\
\hline & $\begin{array}{l}\text { Banka çalışanları arasındaki bağlar güçlü ancak kırılgandır. Kişiler arası sorunlar diğer } \\
\text { çalışanları da etkilemektedir. }\end{array}$ \\
\hline & $\begin{array}{l}\text { Çalışanlar arasında ortak ve paylaşılan bir dil mevcut, birbirilerine karşı nazik ve } \\
\text { olumlular. }\end{array}$ \\
\hline & $\begin{array}{l}\text { Bankada işe yeni başlayanlara anlatılan hikâyeler abartılı, olumsuz ve eğlenceli bir } \\
\text { şekilde aktarılmakta, ders çıkarma işlevi taşımakta, olası hatalara karşı gözdağı } \\
\text { niteliğinde olup çalışma hayatının stres ve sıkıntılarına karşı biraz da eğlendirme } \\
\text { işlevine sahiptir. }\end{array}$ \\
\hline & $\begin{array}{l}\text { Bankanın amacını gerçekleştirmesi için dış çevre ile ilişkilerinin ve imajının önemine } \\
\text { dair farkındalık, müşteri memnuniyeti vurgusu hâkimdir. }\end{array}$ \\
\hline & $\begin{array}{l}\text { Teknoloji konusunda tutarlı değerlendirmeler bulunmamakta, bazılarınca hızlı } \\
\text { bazılarınca ise yetersiz ve yavaş olduğunu düşünülmekte, ancak yenilenmenin } \\
\text { sürdügü konusunda uzlaşma mevcuttur. }\end{array}$ \\
\hline & $\begin{array}{l}\text { Kılık/kıyafet konusunda katı ve sıkı kurallar ve düzen mevcut, çalışanlarda özgürlük- } \\
\text { lerini kısıtlayan bir durum olarak görülmektedir. Kılık kıyafet bankanın imajı ile } \\
\text { bütünleştirilmektedir. }\end{array}$ \\
\hline
\end{tabular}

Bulguların analizi sonrasında bankanın güçlü bir kültüre sahip olduğu söylenebilecektir. Kültürel değerler açısından bakıldığında elitist/geleneksel kültürel değerler tasnifi içerisine yerleştirmek mümkündür. Buna göre yer alan ifadelere bakıldıı̆ında;

"bankanın büyüyen ve büyümeye devam eden yapısı, yol göstericiliği, korunma hissettirecek bir büyüklük, temel ihtiyaç tanımlaması"

"banka tarihine ve geçmişine duyulan güven, köklü geçmişin geleceği şekillendirmesi"

"Bankanın kendini yenilemesi ve büyüyeceğine olan inanç"

"Bankada çalışmanın gurur verici olduğu, devlete ve halka hizmet ettiği" (burada diğer bankalarla karşılaştırıldığında büyük bir kamu bankası olması ve kuruluş amacı düşünülerek yapılan bir değerlendirme olduğu görülebilmektedir) 
Performans- ödül ilişkisine ilişkin analizlerde yeni fikirler ve yenilikçiliğin yönetimce arzu edildiği ancak çalışanlar arasında bir değer olarak yerleşmediği, hata yapanlara ise toleranssızlıkla aslında yönetimin de yenilikçiliği desteklemediği dolayısı ile bankada fonksiyonel bir değer sisteminin henüz oluşmadığı söylenebilecektir. Güç ilişkilerinde banka liderine ilişkin kullanılan olumsuz metaforlar karizmatik bir değer sisteminin olmadığını göstermektedir.

Fonksiyonel değerlere yönelik bir evirilme ve değişim var mıdır gibi bir soru akla gelmektedir. Metafor analizinde yer alan ifadelerde söylenen müşteri odaklılık vurgusu fonsiyonel bir değer olarak düşünülse de arı ve motor gibi metaforlar, aslında bunun içselleştirilen değil görev ve sürekli tekrarlanan bir anlayışı yansıttığını düşündürmektedir. Müşteriler nedeniyle aralarında yoğun ve yıkıcı bir rekabet yaşandığını gösteren ifadeler ve kene, avcı gibi metaforlar da bu olgunun içselleştirilemediğini göstermektedir.

Geleneksel değerler ise kurallar ve hiyerarşik yapı ile aktarılıyor görünmektedir. İletişim başlığı altında da kural ve sorunlar gözlenmektedir.

\section{Sonuç}

Örgüt kültürünün ölçümünde kullanılan mevcut yöntemler alan yazında tartışılmakta, sembolik unsurlara sahip olan örgüt kültürünün ölçülmesinde metaforlar bir yöntem olarak önerilmektedir. Bankalarda örgüt kültürünün metaforlarla analizini amaçlayan bu çalışmada, örgüt kültürü unsurlarının çalışanlar tarafından farklı metaforlarla ifade edildiği ve bu metaforların örgüt kültürüyle ilgili önemli ipuçları verdiği ortaya konulmuştur. Bir kamu bankası örneğinde gerçekleştirilen analiz sonucunda çalışanlar bankayı aile gibi görmekte büyük, güçlü, köklü, büyüyen ve büyümeye devam edecek bir kuruluş olarak nitelendirmektedirler. Banka personeli, banka için değerli olduklarını düşünmekte ve kendilerini banka ile bütünleşmiş hissetmektedirler. Banka çalışanlarının kullanmış oldukları metaforlardan yola çıkılarak güçlü bir örgüt kimliğinin mevcut olduğu söylenebilir.

Performans ödül ilişkisi açısından bakıldığında, örgütteki ödül sisteminin çalışanları yeterince tatmin etmediği, ödüllerin zor ele geçirildiği, alınmasının daha çok şansa ve beklenmedik bir zamana bırakıldığı belirlenmiştir. Çalışanlar ödül sistemini piyango, sadaka, kırbaç gibi metaforlarla ifade etmektedirler. Ödüller adil ancak ödüller ve ödüllere ulaşmak için konulan standartlar yetersiz görülmektedir. Risk üstlenmeyi teşvik açısından örgüt yönetimi yeni fikir ve düşüncelere açıktır. Yeni fikri olanlar nadir ve değerlidir. Ancak hata yapan personelin örgüt tarafından kabul edilmediği hataya yer olmadığı sonucuna ulaşılmaktadır. Yeni fikir ve düşüncesi olanlar Atatürk, filozof ve bilim adamı gibi metaforlarla ifade edilmektedir. Yönetim desteklese de yenilikçi bireylerin diğer çalışanlar tarafından desteklenmediği ve yeniliğe açık olmadıkları görülmektedir. Bankada riski ve yeni fikirleri teşvik etmeyen, hataya toleranssız, mükemmeliyetçi bir kültürün olduğu sonucuna ulaşılmıştır. Bu durum Türkiye'de yaygın olan ulusal kültürden mi beslenmekte yoksa bankaya özgü bir durum mudur sorusu akla gelmektedir. Araştırmalar, bireyci kültürlerin kolektif kültürlere göre yenilikçilik potansiyelinin yüksek olduğunu ortaya koymaktadır. Belirsizlikten kaçınma konusunda da benzer bulgular olup belirsizlikten kaçınma düzeyi yüksek olan toplumlarda yenilikçiliğin düşük olduğu gözlenmektedir. Kolektif ve belirsizlikten kaçınma düzeyi yüksek bir kültür yapısına sahip olan Türkiye'de yenilikçilik düşüktür. Bununla birlikte kolektif toplumlarda yenilikçilik grup içerisinde teşvik edilerek gerçekleştirilebilir (Yeşil,2012). Bu sonuç, bankanın risk üstlenme ve yenilik konusunu, çalışanların ödüller konusundaki algılamaları ile birlikte düşünerek yeniden değerlendirmesi ve çözüm üretmesi gerektiğini ortaya koymaktadır. 
Bankadaki var olan örgüt kültürüne güç ilişkileri açısından bakıldığında, yöneticilerin çalışanlar ile ilişkilerinin hükmedici, katı ve cezalandırıcı olduğu görülmektedir. Yöneticiler için kullanılan baba, aslan, komutan metaforlarıdır. Çalışanlar yöneticilerini koruyucu bir aile reisi gibi görmektedirler. Bu durum Türkiye'de yaygın olan paternalist kültürün bir yansıması olarak değerlendirilebilir. Bankadaki makam odaları gibi fiziksel semboller gücü beslemektedir. Personel kendilerini bankada asli unsur gibi görmekle birlikte kendilerini kontrol ve gözetim altında, vitrinde birer meta olarak görmektedirler. Bu bulgu, bankada personel güçlendirme ve psikolojik güçlendirme algısının düşük olduğunu düşündürmektedir.

Personel ve iş ilişkilerinde çok çalışma, yarışma ve takım ruhunun güçlü olduğu belirtilmekle birlikte zaman zaman birbirlerine zarar verici davranışlarla karşılaşılabilmektedir. Bu durum, takım ruhu konusunda çelişkili sonuçlar olduğunu düşündürmektedir. İş ortamında personel arı, robot, makine gibi metaforlarla nitelendirilmektedir. Bankada, müşteri odaklılık vurgusu yapılmakta ancak çalışanlar arası ilişkilerde yıkıcı bir rekabet yarattığı ifade edilmektedir. İş ilişkileri açısından stresli, sürekli çalışma gerektiren, talimatlarla çalışılan, yorucu, yıpratan, tüketen ve yaşamdan kopuk bir çalışma düzeni olduğu belirtilmektedir. Bu açıklamalar yapılan işin ve sektörün bir özelliği olarak da değerlendirilebilir. Ancak çalışanlar bu çalışma düzeni içerisinde mizahi ve eğlenceli yanlar da bulabilmektedir. Bu davranış biçimi bankanın kültürü açısından olumlu bir durum olarak düşünebilir.

Örgüt yapısına ilişkin değerlendirmelere göre banka çalışanları, örgütteki hiyerarşik kademeler arasında katı ve uyulması zorunlu kurallar olduğunu, örgüt içindeki birçok davranışın bu kurallara göre şekillendiğini, uyulmaması halinde cezaya katlanılması gerektiğini ifade etmektedirler. Bankadaki hiyerarşik kıdemler arasındaki ilişki ile ilgili belirtilen metaforların \%77,6'sı olumsuzdur. Kullanılan bazı metaforlar askeriye, kanun ve buzdur. Bankanın büyüklüğü düşünüldüğünde yapının bu kurallar ile sağlanması beklenen bir bulgudur. Ancak çalışanlar, olması gerektiğine ve düzeni sağladığına inansalar da bu kuralları rahatsız edici bulmaktadırlar. Bu sonuç, kuralların uygulanmasında demokratik bir tarzdan uzak olunduğunu düşündürmektedir. 2011-2012 Türkiye değerler Araştırması sonuçları demokrasinin sözde yerleştiği ama özde hala otokrat bir değer sisteminin hâkim olduğu bulgusu yer almaktadır (Esmer,2012:66). Bu çalışmanın amaçları arasında, makro kültürün bankadaki değerler ile nasıl etkileşim içerisinde olduğu, benzeşen ve farklılaşan yönlerini araştırmak yer almamakla birlikte, bu yapıyı açıklayan bir bulgu olarak değerlendirilebilir.

Örgüt kültürünün iletişim boyutunda bölümler arası ilişkinin yapılan işin gereği olarak birbirine bağlı olmak zorunda olduğu, bölümler arasında yaşanan olumsuzlukların diğer bölümleri de etkilediği görülmektedir. Bölümler arasındaki ilişki zincir, halat, ince ip gibi metaforlar ile ifade edilmektedir. Illetişimde kuruluş içerisindeki haberler hızla yayılmakta ve abartılabilmektedir. Törenler çoğunlukla ayrılma zamanlarında yapılmakta, bütünleştirici ama zaman zaman da rahatsızlık verici olarak nitelendirilmektedir. Banka çalışanları arasında kendilerine özgü ve nezaketin hâkim olduğu bir dil bulunmaktadır.

Bankayla ilgili hikâyeler abartılarak ve eğlenceli bir şekilde anlatılmakta ve ders çıkarma işlevi taşımaktadır. Bankada işe yeni başlayanlara bankayla ilgili anlatılan hikâyeler ile ilgili belirtilen metaforların çoğu olumsuzdur. Anlatılan hikâyeler efsane, korku filmi, roman gibi metaforlarla ifade edilmektedir. Örgütte yeni işe başlayanların acemi oldukları ve kendilerini ispat etmekle meşgul oldukları vurgulanmaktadır. Örgüte uyum sağlama sürecindeki çalışanlar, yeni öğrenmeye başladıkları kültürde diğer çalışanların nelere değer verdiklerini, neler için uyuşmazlık yaşadıklarını, anlaşmazlıklarda nasıl davranacaklarını öğrenerek, örgüt tarafından be- 
nimsenmeyen değerleri bırakarak yeni örgüte kısa zamanda uyum sağlama çabasındadırlar. Çalışanlar kendilerini örgüte yakın, ayrılmaz birer parça olarak görmektedirler. Bankanın kılık/kıyafet düzeninde katı kurallar bulunmaktadır. Bu doğrultuda banka için ortak hedef, takım halinde çalışma, bölümler arası rekabetçilik, nazik ve olumlu ortak bir dil, giysi kuralları ile imaj ve müşteri memnuniyeti çıkarımı yapılabilecektir.

Metafor analizi sonrasında elde edilen bulgular bankada güçlü bir örgüt kültürünün varlığını ortaya koymaktadır. Weiner'in (1988) değer sınıflamasına göre ise bankanın elitist/geleneksel değerlerin hâkim olduğu bir örgüt olduğu söylenebilir. Fonksiyonel değerlere sahip örgütlerin elitist değerlere göre daha etkili bir yönetim sağladığı yazında önerilmektedir. Ancak önemli olan fonksiyonel değerlerin içselleştirilmesidir.

Araştırma sonucunda örgüt kültürü unsurları çalışanlar tarafından farklı metaforlarla ifade edilmekte ve bu metaforların analizi ile örgüt kültürüyle ilgili derinlemesine ve önemli ipuçlarına ulaşıldığı görülmektedir. Kültürü, kişilerin paylaştığı semboller ve anlamlar olarak gören çağdaş antropologlar bu kavramı açıklayabilmek için yerel bakış açısını kavramanın önemini vurgularken, bu konuda temel araçlar olarak dil ve semboller üzerine yoğunlaşmaktadır. Bu görüşe göre insanlar, sosyal ve fiziksel dünyalarını sembolik süreçler aracılığıyla kurarlar ve bir sosyal grubun üyeleri, dünyaya anlam yüklemek için aynı kodları paylaştıkları derece benzer davranırlar (Barley, 1983:398).

Metaforlar, insanların gerçekle ilişkilerinde önemli bir yer tutan araçlardır. Örgütü çözümlemede kültürü bir metafor olarak ele alanlar, örgütleri, ekonomik, politik, teknik, fiziksel kavramlarla çözümlemenin ötesinde, paylaşılan inançlar, değerler, semboller gibi daha çok soyut kavramlarla açıklamaya ve çözümlemeye çalışmakta, örgütsel yaşamın öznel yönüne ağılık vermektedirler (Şişman, 2011:110). Yapılan araştırma sonucunda kullanılan metaforların; örgüt yöneticilerine örgüt kültüründe olumlu ve olumsuz yönde öne çıkan kültürel faktörlerin işaretini verebileceği, metaforların kullanımları arasındaki farklılık, örgüt kültüründe ortak algılanan bir kültürün olup olmadığını ortaya çıkarabileceği, örgüte yeni katılacak üyelerin, örgüte daha çabuk uyum göstermelerinin sağlanabileceği, örgütün ne olduğu, ne olması ve nasıl yönetilmesi gerektiği konularında önemli ipuçları vereceği belirlenmiştir. Bankacılık sektörü Türkiye'de finans sektöründe önemli bir yer tutmaktadır. Gerek rekabet üstünlüğü gerekse birleşme ve satın almalar sonrası yaşanan kültürel uyum sorunlarının çözümünde bankalarda örgüt kültürünün analizi ve uygun analiz yönteminin kullanılması önemli ipuçları sağlamaktadır.

Örgüt kültürünün bu tür bir yöntemle ölçümlenmesi, özellikle birleşme ve satın almaların sıklıkla yaşandığı bankacılık sektöründe kültürel uyumu sağlama açısından danışmanlar ve yöneticilere açıklayıcı bilgiler sunacaktır. Bu tür bir analiz ile örgütte ortak algılanan bir kültürün olup olmadığı belirlenerek, örgüte yeni katılan üyelerin örgüte daha çabuk uyum göstermeleri için neler yapılabileceği, örgüt üyelerinin çalışmış oldukları örgütle bütünleşememe nedenleri, bölümler arasındaki ve ast-üst ilişkilerindeki iletişim problemlerinin neler olduğu, örgütteki ödüllendirme-ceza sisteminin sorunları ortaya konulabilecek ve alınacak önlemlerle örgütün daha etkili çalışması sağlanacaktır. Yapılan çalışmanın personelin işe alım sürecinden sonra örgüte uyum sağlamasında, örgüt içinde yaşanan iletişim problemlerinin anlaşılmasında ve çözümlenmesinde, daha etkili bir örgüt kültürü oluşturulması için yol gösterici olacağı düşünülmektedir. Kullanılan yöntem diğer sektörlerde de örgüt kültürün tespitinde yararlı sonuçlara ulaşılmasını sağlayacaktır. 
Örgüt kültürü ile makro kültür ve değerler arasındaki ilişkiler bir başka araştırma sorusu olarak sonraki çalışmalarda araştırılabilir. Çalışma bazı kısıtlar taşımaktadır. Araştırmada, incelenen bankanın belirli bir bölgedeki şubelerinden elde edilen verilerle yorumlama yapılmıştır. Nitel çalışmalar için genellenebilirlik gibi bir kaygı olmamakla birlikte söz konusu örgüt kültürü için merkez şubelerden de veriler alınması sonuçları zenginleştirecektir. 


\section{Kaynaklar}

ALPASLAN, S.(2007),"Sanayi ve Bilgi Toplumu Yönetim Metaforlarının Karşılaştıııması", TC Sakarya Üniversitesi Sosyal Bilimler Enstitüsü Yüksek Lisans Tezi, Sakarya.

BARLEY, R.S.(1983),"'Semiotics and the Study of Occupational and Organizational Cultures", Administrative Science Querterly, 28 (3), 393-413.

BíLLUPS, F.D. (2011a),"Exploring Organizational Culture Through Metaphor Analysis, Higher Education", Paper 8. http://scholarsarchive.jwu.edu/highered/8 (Erişim Tarihi,24.12.2015).

BiLLUPS, F.D. (2011b),"'Collegiate Administrator Perceptions of Organizational Culture: An Analysis of Metaphors ", NERA Conference Proceedings. http://digitalcommons.uconn.edu/nera_2011/12 (Erişim Tarihi,24.12.2015).

BLOISI, W. , COOK, C.W. ve HUNSAKER, P.L. (2003), Management and Organizational Behavior, McGraw Hill, London.

COŞKUN,M.N.,ARDOR,H.N.,ÇERMIKLi,H.,ERUYGUR,H.O.,ÖZTÜRK,F.,TOKATLIOĞLU,I.,AYKAÇ,G ve DAĞLAROĞLU,T. (2012), "Türkiye'de Bankacılık Sektörü Piyasa Yapısı, Firma Davranışları ve Rekabet Analizi" ,Türkiye Bankalar Birliği Yayın No.280, İstanbul.

CRESWELL, J.W. (2016), Nitel Araştırma Yöntemleri, Çev. Ed. M. Bütün ve S.B. Demir, Siyasal Kitabevi, Ankara.

DANIŞMAN, A. ve ÖZGEN,H. (2003), “Örgüt Kültürü Çalışmalarında Yöntem Tartışması: NicelikselNiteliksel Yöntem İkileminde Niceliksel Ölçümler ve Bir Ölçek Önerisi”, Yönetim Araştırmaları Dergisi, 3(2), 91-124.

ERDEM, F. ve ŞATIR, Ç. (2000),"Farklı Örgütlerde Kültürel Yapının Metaforlarla Analizi", Nevşehir: 8.Ulusal Yönetim ve Organizasyon Kongresi, 25-27Mayıs, Erciyes Üniversitesi.

ERDEM, F. (2010), “Örgüt kültürünün kök metaforlarla keşfi: Üniversite gerçekliği üzerine nitel bir araştırma", Yönetim Araştırmaları Dergisi, 10 (1-2), 71-96.

ERKMEN, T. (2000),,"Örgüt Kültürü ve Ölçümü", Yönetim, 11(35),Ocak, 23-33.

ESMER, Y. (2012), Türkiye Değerler Atlası, https://www.academia.edu/9620697/T\%C3\%BCrkiye_De\%C4\%9Ferler_Atlas\%C4\%B1_2012, Erişim Tarihi: 14.12.2016.

EVCiM, U.(2008),,'Örgüt Kültürünün Algılanmasında Metaforların Rolü” ,TC Gazi Üniversitesi Sosyal Bilimler Enstitüsü Yüksek Lisans Tezi, Halkla illişkiler ve Tanıtım Anabilim Dalı, Ankara.

Fiş, A.M. ve WASTi, S.A. (2009),"Örgüt kültürü ve girişimcilik yönelimi ilişkisi", ODTÜ Gelişme Dergisi,( 35)127-164.

GiziR, S. (2003), "Örgüt kültürü çalışmalarında yöntemsel yaklaşımlar”, Kuram ve Uygulamada Eğitim Yönetimi, 35, 374-397.

HAMMAL, G.ve VADI,M. (2010),"'Diagnosic Organizationa Culture Through Metaphors and Task and Taskrelation Shiporientations, Organizational Culture Through Metaphorsand Orientations", TheUniversity of Tartu FEBA.www.mtk.ut.ee/research/workingpapers.(Erişim tarihi:24.12.2015).

MUTLU, E. (2004), iletişim Sözlüğü, Ankara: Bilim ve Sanat Yayınları.

PALMER, I. ve LUNDBERG, C.C. (1995), "Metaphors of hospitality organizations", Cornel Hotel and Restaurant Administration Quarterly.36(3), 80-85.

PETTiGREW, A.M. (1979),"On Studying Organizational Cultures, Administrative Science Quarterly", 24 (4), 570-581.

ROBBINS, S.P. ve COULTER,M. (1996), Management, Prentice Hall Inc.,NewJersey.

ROBBinS, S.P., DECENZO,D.A. ve COULTER,M. (2013), Yönetimin Esasları, Çev.Ed. A.Öğüt, Nobel Yayınla$\mathrm{rI}$, Ankara.

SARGUT, A.S.(2001), Kültürler Arası Farklılaşma ve Yönetim, Ankara: İmge Kitapevi Yayınları. 
SCHEiN, E.H.(2002),"Örgütsel Kültür", Çev: Akbaba, A. Dokuz Eylül Üniversitesi Sosyal Bilimler Enstitüsü Dergisi,4(3), (Orijinal makalenin yayım tarihi 1990), 1-32.

ŞiŞMAN, M.(2011), Örgütler ve Kültürler, (3.Basım), Ankara: Pegem Akademi.

TAMiMi, Y.(2005),"'Örgüt kültürünün metaforlarla analizi (Tekstil Sektöründe faaliyet gösteren bir işletme örneği)','Eskişehir Osmangazi Üniversitesi Sosyal Bilimler Enstitüsü, Yüksek Lisans Tezi, Eskişehir.

THAKOR, A. (2016), Corporate Culture in Banking, FRBNY Economic Policy Review, August, 5-16.

THOM, N.(1990)," Innovation Management in Small and Medium-Sized Firms" Management International Review,30-182.

WEINER, Y. (1988), "Forms of Value Systems: A Focus on Organizational Effectiveness and Cultural Change and Maintenance", Academy ol Management Review, 13 (4), 534-545.

YAĞMURLU, A. (1997),"Örgüt Kültürü: Tanımlar ve Yaklaşımlar", Ankara Üniversitesi SBF Dergisi, 52(1),717-724.

YEŞiL, S. (2012), "Türkiye'nin Ulusal Kültürel Özellikleri ve Yenilikçilik Potansiyeli Arasındaki illişki Açısından Bir Değerlendirme", Mustafa Kemal Üniversitesi Sosyal Bilimler Enstitüsü Dergisi, 9 (17), 33-62.

YILDIRIM, A. ve ŞiMŞEK, H. (2013), Sosyal Bilimlerde Nitel Araştırma Yöntemleri. Ankara: Seçkin Yayıncılık. 